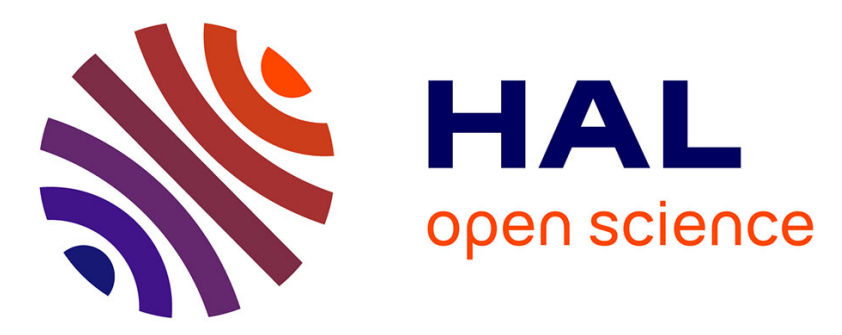

\title{
Eicosanoid formation by a cytochrome P450 isoform expressed in the pharynx of Caenorhabditis elegans
}

\author{
Mandy Kosel, Waltraud Wild, Alexandra Bell, Michael Rothe, Carsten
}

Lindschau, Christian E.W. Steinberg, Wolf-Hagen Schunck, Ralph Menzel

\section{- To cite this version:}

Mandy Kosel, Waltraud Wild, Alexandra Bell, Michael Rothe, Carsten Lindschau, et al.. Eicosanoid formation by a cytochrome P450 isoform expressed in the pharynx of Caenorhabditis elegans. Biochemical Journal, 2011, 435 (3), pp.689-700. 10.1042/BJ20101942 . hal-00586471

\section{HAL Id: hal-00586471 \\ https://hal.science/hal-00586471}

Submitted on 16 Apr 2011

HAL is a multi-disciplinary open access archive for the deposit and dissemination of scientific research documents, whether they are published or not. The documents may come from teaching and research institutions in France or abroad, or from public or private research centers.
L'archive ouverte pluridisciplinaire HAL, est destinée au dépôt et à la diffusion de documents scientifiques de niveau recherche, publiés ou non, émanant des établissements d'enseignement et de recherche français ou étrangers, des laboratoires publics ou privés. 


\section{EICOSANOID FORMATION BY A CYTOCHROME P450 ISOFORM EXPRESSED IN THE PHARYNX OF CAENORHABDITIS ELEGANS}

Mandy Kosel $^{* \dagger 1}$, Waltraud Wild ${ }^{\dagger 1}$, Alexandra Bell ${ }^{\dagger}$, Michael Rothe ${ }^{\ddagger}$, Carsten Lindschau ${ }^{\S}$, Christian E. W. Steinberg ${ }^{\dagger}$, Wolf-Hagen Schunck ${ }^{*}$ and Ralph Menzel ${ }^{\dagger 2}$

* Max Delbrück Center for Molecular Medicine, Robert-Rössle-Str. 10, 13125 Berlin, Germany

${ }^{\dagger}$ Humboldt-Universität zu Berlin, Department of Biology, Freshwater and Stress Ecology, Spaethstr. 80/81, 12437 Berlin, Germany

* Lipidomix GmbH, Robert-Rössle-Str. 10, B55, 13125 Berlin, Germany

${ }^{\S}$ Hannover Medical School and Medical Faculty of the Charité, Experimental and Clinical Research Center, Robert-Rössle-Str. 10, 13125 Berlin

${ }^{1} \mathrm{MK}$ and WW contributed equally

${ }^{2}$ To whom correspondence should be addressed (email ralph.menzel@biologie.hu-berlin.de).

SHORT TITLE: CYP-dependent EPA metabolism in Caenorhabditis elegans 


\title{
SYNOPSIS
}

Caenorhabditis elegans harbours several cytochrome P450 (CYP) genes that are homologous to mammalian CYP isoforms important to the production of physiologically active arachidonic acid (AA) metabolites. We tested the hypothesis that mammals and C. elegans may share similar basic mechanisms of CYP-dependent eicosanoid formation and action. We focused on CYP33E2, an isoform related to the human AA-epoxygenases CYP2C8 and CYP2J2. Co-expression of CYP33E2 with the human NADPH-CYP-reductase in insect cells resulted in the reconstitution of an active microsomal monooxygenase system that metabolized eicosapentaenoic acid (EPA) and, with lower activity, also AA to specific sets of regioisomeric epoxy- and hydroxyderivatives. Main products included 17,18-epoxyeicosatetraenoic acid from EPA and 19hydroxyeicosatetraenoic acid from AA. Using worms carrying a CYP33E2 promoter::GFPreporter construct, we found that CYP33E2 is exclusively expressed in the pharynx, where it is predominantly localized in the marginal cells. RNAi-mediated CYP33E2 expression silencing as well as treatments with inhibitors of mammalian AA-metabolizing CYP enzymes, significantly reduced the pharyngeal pumping frequency of adult worms. These results demonstrate that EPA and AA are efficient CYP33E2 substrates and suggest that CYP-eicosanoids, influencing in mammals the contractility of cardiomyocytes and vascular smooth muscle cells, may function in C. elegans as regulators of the pharyngeal pumping activity.

KEYWORDS: $\quad$ Eicosanoids; Long-chain polyunsaturated fatty acids; Caenorhabditis elegans; Cytochrome P450; Eicosapentaenoic acid; Arachidonic acid

\begin{abstract}
ABBREVIATIONS USED: CYP, cytochrome P450; AA, arachidonic acid; EPA, eicosapentaenoic acid; GFP, green fluorescent protein; RNAi, RNA interference; LC-PUFAs, Long-chain n-6 and n-3 polyunsaturated fatty acids; COX, cyclooxygenases; LOX, lipoxygenase; 17-ODYA, 17-octadecynoic acid; PPOH, 6-(2-Propargyloxyphenyl) hexanoic acid; hCPR, human NADPH-CYP reductase; LA, lauric acid; RP-HPLC, reversed-phase high performance liquid chromatography; NP-HPLC, normal-phase high performance liquid chromatography; CPHPLC, chiral-phase high performance liquid chromatography; EEQ, Epoxyeicosatetraenoic acid; LC-MS, liquid chromatography/mass spectrometry; CID, Collision-induced dissociation; HETE, Hydroxyeicosatetraenoic acid EET, Epoxyeicosatrienoic acid; HEET, Hydroxyepoxyeicosatrienoic acid; DHET, Dihydroxyeicosatrienoic acid; HEPE,
\end{abstract} Hydroxyeicosapentaenoic acid 


\section{INTRODUCTION}

Long-chain n-6 and n-3 polyunsaturated fatty acids (LC-PUFAs) such as arachidonic acid (AA; 20:4 n-6) and eicosapentaenoic acid (EPA; 20:5 n-3) are essential for health and development of animals. Whereas n-6 and n-3 PUFAs are accessible to mammals only via nutrition, the nematode Caenorhabditis elegans has the capacity to de novo synthesize both classes of these important fatty acids $(1,2)$. Moreover, unlike plants, PUFA de novo synthesis in $C$. elegans does not end at the level C18 fatty acids but proceeds further to yield AA and EPA as main products. This makes $C$. elegans an attractive model to analyze the multiple physiological functions of LCPUFAs. Loss of function mutations in LC-PUFA biosynthesis genes result in pleiotropic defects including mechanosensory, osmosensory and olfactory deficits (3). Worms lacking a functional delta- 6 desaturase (encoded by the fat-3 gene) are unable to synthesize any fatty acid beyond linoleic (18:2 n-6) and linolenic acid (18:3n-3) leading to reduced brood size and neuromuscular defects $(1,2,4)$. Fat-3(wa22) mutants also show reduced pharyngeal pumping activity suggesting that AA and EPA are involved in the regulation of pharynx activity (4). Nearly all these deficits can be rescued by feeding the mutant worms with the missing LC-PUFAs (4). Moreover, LCPUFAs are necessary for signalling in oocytes during recruitment of sperm to the spermatheca (5). These data indicate important roles of LC-PUFAs for various behavioural and developmental capacities of $C$. elegans. However, the molecular mechanisms of how LC-PUFAs contribute to these fundamental processes are largely unclear.

In general, LC-PUFA actions may include direct effects on membrane structures, ion channels and transcription factors. Moreover, LC-PUFAs may serve as precursors of eicosanoids and other signalling molecules. In mammals, eicosanoid biosynthesis proceeds via three pathways that are initiated by cyclooxygenases (COX), lipoxygenases (LOX) and cytochrome P450 (CYP) enzymes (6,9-12). Interestingly, C. elegans does not contain any obvious orthologs of mammalian COX and LOX enzymes or of prostanoid and leukotriene receptors $(7,8)$. However, the C. elegans genome harbours 75 potentially functional CYP genes compared to 57 in human and 102 in mouse (13). In particular, members of the C. elegans CYP-families CYP29 and CYP33 show significant amino acid sequence homologies to mammalian CYP4A/4F and CYP2C/2J isoforms that function as AA-hydroxylases and AA-epoxygenases, respectively (14). We demonstrated that epoxy- and hydroxy-metabolites of AA and EPA are endogenous constituents of $C$. elegans (14). Moreover, we found that these metabolites are produced by a microsomal monooxygenase system that can be blocked by typical inhibitors of mammalian CYP-dependent AA metabolism such as 17-octadecynoic acid (17-ODYA) and 6-(2propargyloxyphenyl) hexanoic acid (PPOH). Our gene silencing experiments revealed the emb-8 (15) gene encoded NADPH-CYP reductase (16) as the essential electron transfer component and identified CYP29A3 and CYP33E2 as the most likely candidates for catalyzing the metabolism of AA and EPA in C. elegans (14). Extending the parallels between C. elegans and mammals, the nematode also expresses soluble epoxide hydrolases that metabolize CYP-dependent epoxymetabolites of diverse PUFAs (17).

Based on these findings, we hypothesized that C. elegans and mammals may share common mechanisms of CYP eicosanoid biosynthesis and action. This would provide the opportunity of using C. elegans as a model organism to facilitate the identification of the primary targets of CYP eicosanoids and the elucidation of signalling pathways mediating their physiological functions. As a first step to address these questions, we have now focused on 
CYP33E2 and analyzed the substrate specificity and cellular localization as well as the potential role of this CYP isoform in the regulation of the pharyngeal activity in C. elegans.

\section{EXPERIMENTAL}

\section{Nematode strain and cultivation condition}

The C. elegans wild type strain Bristol N2 and the mutants fat-1 (wa9) and fat-3(wa22) were used throughout this study. The nematodes were grown at $24^{\circ} \mathrm{C}$ on nematode growth medium (NGM) agar plates inoculated with Escherichia coli OP50 as food source (18) and were incubated on similar conditions as described before (14).

\section{Amplification and cloning of the $C Y P 33 E 2$ cDNA}

Reverse transcription of $4 \mu \mathrm{g}$ total RNA was performed at $50^{\circ} \mathrm{C}$ for $30 \mathrm{~min}$ using the Transcriptor High Fidelity cDNA Synthesis Sample Kit (Roche, Germany). Subsequently, PCR amplification of the CYP33E2 cDNA was performed using the Phusion ${ }^{\circledR}$ High Fidelity DNA Polymerase (Finnzymes, USA) and the following primer pair: FP-33E2 5'CTCTGTTAGAATGATATTATTTATTG-3' and RP-33E2 5'GGTTATAAACAACACAAATTTTTCATG-3'. After Taq polymerase-mediated generation of 3 '-adenosine overhangs, the PCR product was cloned into the $\mathrm{PCR}^{\circledR} 2.1$-TOPO vector using the TOPO TA Cloning Kit (Invitrogen, Germany).

\section{Generation of recombinant baculoviruses}

The CYP33E2 cDNA was recloned from $\mathrm{pCR}^{\circledR} 2.1-\mathrm{TOPO}$ into the $\mathrm{pFastBac}^{\mathrm{TM}} 1$ vector (Invitrogen, Germany) using the restriction enzymes HindIII and NotI. The identity of CYP33E2 cDNA was confirmed by full length sequencing of both DNA strands, performed by LGC Genomics (Germany). Recombinant baculoviruses containing the CYP33E2 cDNA under control of the strong polyhedrin promoter were produced using the Bac-to-Bac ${ }^{\circledR}$ Baculovirus Expression System from Invitrogen, Germany. After re-amplification in Spodoptera frugiperda (Sf9) cells, a virus titre of about $1-3 \times 10^{9}$ was achieved.

\section{CYP33E2 expression in insect cells and preparation of enzymatically active microsomes}

Sf9 cells were grown in ExCell 420 medium (Sigma-Aldrich, Germany) supplemented with 10 $\%$ heat-inactivated fetal calf serum, $50 \mathrm{U}$ penicillin $/ \mathrm{ml}$, and $50 \mu \mathrm{g}$ streptomycin $/ \mathrm{ml}$. After reaching a cell density of $1.8 \times 10^{6}$ cells $/ \mathrm{ml}$, the cultures were co-infected with the recombinant baculoviruses prepared for the expression of CYP33E2 and of the human NADPH-CYP reductase (hCPR), essentially as described previously for the generation of other CYP-hCPR monooxygenase systems (19). In control experiments, the cultures were infected with an empty baculovirus or with either the CYP33E2- or hCPR-baculovirus alone. $24 \mathrm{~h}$ after infection, the medium was supplemented with $5 \mu \mathrm{M}$ hemin chloride and $100 \mu \mathrm{M}$ riboflavin. The cells were harvested after further $24 \mathrm{~h}$, resuspended in ice-cold $0.1 \mathrm{M}$ potassium phosphate buffer, $\mathrm{pH} 7.4$, containing $20 \%$ glycerol, $1 \mathrm{mM}$ EDTA, $0.5 \mathrm{mM}$ DTT, $100 \mu \mathrm{M}$ PMSF and $1 \mu \mathrm{M}$ of both FAD and FMN. The harvested cells were lysed by brief sonification. Microsomes were prepared at $4^{\circ} \mathrm{C}$ by differential centrifugation $(5 \mathrm{~min}$ at $3,000 \mathrm{~g} ; 10 \mathrm{~min}$ at $10,000 \mathrm{~g}$ and $65 \mathrm{~min}$ at $100,000 \mathrm{~g}$ ). The microsomes were resuspended and homogenized in $0.1 \mathrm{M}$ potassium phosphate buffer $\mathrm{pH}$ 
7.4 containing $20 \%$ glycerol, $1 \mathrm{mM}$ EDTA, $0.5 \mathrm{mM}$ DTT, shock frozen in liquid nitrogen and stored in aliquots at $-80^{\circ} \mathrm{C}$.

The microsomal protein concentration was measured according to Lowry et al. (20). The CYP content was determined by carbon monoxide difference spectra using a difference extinction coefficient of $91 \mathrm{mM}^{-1} \mathrm{~cm}^{-1}$ for the wavelength pair $450 \mathrm{~nm}$ minus $490 \mathrm{~nm}$ (21). The hCPR content was estimated as NADPH-cytochrome $c$ reductase activity using a difference extinction coefficient at $550 \mathrm{~nm}$ of $21 \mathrm{mM}^{-1} \mathrm{~cm}^{-1}$ (22). To calculate the reductase content, it was assumed that 4.5 units ( $\mu \mathrm{mol}$ cytochrome $c / \mathrm{min}$ ) correspond to $1 \mathrm{nmol}$ of hCPR (23).

\section{Microsomal fatty acid metabolism}

$\left[1-{ }^{14} \mathrm{C}\right]$-labeled AA $(53 \mathrm{mCi} / \mathrm{mmol})$, EPA $(55 \mathrm{mCi} / \mathrm{mmol})$ and lauric acid (LA; $\left.57 \mathrm{mCi} / \mathrm{mmol}\right)$, having radiochemical purities $>99 \%$, were purchased from Hartman Analytical GmbH (Braunschweig, Germany). To analyze the whole range of primary and secondary metabolites produced by CYP33E2, reactions were performed in $200 \mu \mathrm{L} 100 \mathrm{mM}$ potassium phosphate buffer, $\mathrm{pH} 7.2$, containing $50 \mathrm{pmol} \mathrm{CYP}$ and the respective substrates at a final concentration of $20 \mu \mathrm{M}$. The recombinant microsomal enzyme was pre-incubated with the substrates for $5 \mathrm{~min}$ at $25^{\circ} \mathrm{C}$. The reactions were started with NADPH ( $1 \mathrm{mM}$ final concentration $)$ and terminated after $30 \mathrm{~min}$ shaking at $25^{\circ} \mathrm{C}$ by adding $10 \mu \mathrm{L}$ of $0.4 \mathrm{M}$ citric acid. Controls included omission of NADPH from the reaction mixtures and the use of microsomes lacking CYP33E2, hCPR or both of these components.

Kinetic analysis of CYP33E2 catalyzed substrate conversions was performed using EPA, $\mathrm{AA}$ and LA at concentrations of 5,10,20,40 and $80 \mu \mathrm{M}$. The reactions were terminated after 5 $\mathrm{min}$ in order to analyze product formation in the linear range of substrate conversion and to avoid the formation of secondary metabolites. The reactions were performed in triplicate for each substrate concentration.

\section{Analysis of the metabolite profile}

The reaction products were extracted into ethyl acetate and analyzed in a first step by reversedphase (RP)-HPLC essentially as described previously (23-25). Both EPA and AA metabolites were resolved using a Nucleosil 100-5C18 HD column (250x4 mm; Macherey-Nagel, Germany) and a linear solvent gradient of acetonitrile/water/acetic acid (50:50:0.1, v/v/v) to acetonitrile/acetic acid (100:0.1, v/v/v) over $40 \mathrm{~min}$ at a flow rate of $1 \mathrm{~mL} / \mathrm{min}$ (23). LA metabolites were esterified with diazomethane and resolved with a linear gradient of acetonitrile/water/acetic acid (29.5:70.5:0.1, v/v/v) to acetonitrile/water/acetic acid (59.5:40.5:0.1, $\mathrm{v} / \mathrm{v} / \mathrm{v})$ over $30 \mathrm{~min}$ followed by $15 \mathrm{~min}$ acetonitrile/acetic acid $(100: 0.1, \mathrm{v} / \mathrm{v})$ at a flow rate of 1 $\mathrm{mL} / \mathrm{min}$. (25). Metabolites were detected and quantified using a radio flow detector. Authentic standard compounds were prepared and used as described previously $(23,24)$.

The regioisomeric hydroxy- and epoxy-metabolites of EPA and AA were collected from RP-HPLC and further resolved by normal-phase (NP)-HPLC according to established procedures (23). Chiral-phase (CP)-HPLC served to separate the enantiomers of 17,18epoxyeicosatetraenoic acid (17,18-EEQ) and was done using a Chiralcel OB column $(250 \times 4.6$ mm Daicel, UK) as described previously (24).

Selected metabolites with uncertain identity were further analyzed by liquid chromatography-mass spectrometry (LC-MS) using the triplequadrupole tandem mass spectrometer Agilent 6460 combined with an Agilent 1200 HPLC-System. The spectrometer was equipped with a jet stream electrospray ionization source, operated in negative mode. A Zorbax 
Eclipse Plus-C18 2.1 × $150 \mathrm{~mm} \times 3.5 \mu \mathrm{m}$ column was used as stationary phase and acetonitrile/aqueous ammonium acetate solution $(0.01 \mathrm{~mol} / \mathrm{L})$ as mobile phase. Acetonitrile was increased from 5 to $95 \%$ during the first $10 \mathrm{~min}$ and held for a further $10 \mathrm{~min}$. The injection volume was $5 \mu \mathrm{L}$. A single stage MS measurement with a fragmentor voltage of $130 \mathrm{~V}$ was performed first to identify the molecular ion weights of the reaction products in question. Then, a product ion scan of the molecular ions was carried out at a collision energy of $10 \mathrm{~V}$. The retention times and fragments in the collision-induced dissociation (CID) mass spectra were compared with known fragment patterns of this or similar compounds.

\section{Determination of the endogenous CYP-eicosanoid profile}

The CYP-eicosanoid profile was determined for the wild-type as well as fat-1(wa9) and fat3(wa22) mutant strains (three independent cultures per strain). The nematodes were harvested and prepared for LC-MS/MS analysis essentially as described previously (14). Briefly, aliquots corresponding to $30 \mathrm{mg}$ wet weight were mixed with internal standard compounds (10 ng each of 20 -HETE- $d_{6}, 14,15$-EET- $d_{8}$ and 14,15-DHET- $d_{11}$; from Cayman Chemicals) and subjected to alkaline hydrolysis followed by solid phase extraction of the metabolites. HPLC and MS conditions as well as the multiple reaction monitoring for the analysis of the CYP-eicosanoid profile were exactly as described previously (23).

\section{GFP constructs and transgenic line}

A $1.2 \mathrm{~kb}$ promoter region of CYP33E2 was amplified using the Expand high fidelity PCR system (Roche, Germany) (forward primer: 5'-GTGCAAATTGCGGGTTCTAC-3', reverse primer 5'TCTGAAAAGAGAAAATTAAAAAAAAATTTC-3'), cloned into Promega's pGEM-T vector, and re-cloned by using the $S p h \mathrm{I}$ and $\mathrm{XbaI} / \mathrm{SpeI}$ sites into the plasmid pPD97.78 (Addgene, Cambridge, MA, USA), a worm expression vector containing the GFP gene. The correctness of the construct was confirmed by DNA sequencing. Young adult pha-1(e2123ts) worms were transfected by shooting plasmid (recombinant pPD97.78 and pha-1 wild type allele containing pBX) coated gold particles into the gonads using a gene gun (26). Second generation L1transformants expressing the wild type $p h a-1$ allele were selected at the restrictive temperature of $25^{\circ} \mathrm{C}$. GFP expression was confirmed using a fluorescence microscope (Eclipse E200, Nikon, Japan).

\section{Confocal microscopy}

Individually picked worms were transferred to an agarose pad (a microscope slide coated with a $200 \mu \mathrm{m}$ thick $3 \%$ agarose layer), immobilized by adding $50 \mu \mathrm{M}$ tetramizole hydrochloride (Sigma-Aldrich, Germany) and finally covered with a glass cover slip. For confocal microscopy a BioRad MRC1024 (Biorad, Munich, Germany) with an argon-krypton laser attached to Nikon Diaphot (Nikon, Tokyo, Japan) inverted microscope was used. At least 5 to 10 worms were analyzed from four different cultivations by 10-40x magnifications. Z-stacks were collected at different step-sizes using the LaserSharp software. Image analysis was done using Huygens Essential software from SVI (Hilversum, Netherlands) and ImageJ (public domain, NIH, Bethesda, USA).

\section{Pharyngeal pumping rate and RNA interference}

At the $3^{\text {rd }}$ day of adulthood the pharyngeal pumping rate was quantified. Nematodes of the different treatments were randomly selected $(n \geq 10)$ and the pumping frequency was determined 
three times over a $15 \mathrm{~s}$ time span. For each assay three independent experimental trials were performed. In case of the fat-3 experiments, the bacterial food was supplemented with EPA, AA (each $1 \mu \mathrm{g} / \mathrm{ml}$ ) or kept unchanged. The CYP33E2 RNA interference (RNAi) by feeding experiment, as well as the attendant test of its efficiency by qRT-PCR, followed exactly the protocol described by Kulas et al. (14). The HT115(DE3) feeding strain carrying the empty L4440 vector served as control. For testing the effect of CYP inhibition on the pumping rate, the nematodes were transferred to fresh plates and pre-treated for $24 \mathrm{~h}$ with 17-ODYA (27) or PPOH (28) (both from Cayman Chemical via Biomol, Hamburg, Germany). The compounds were directly added to the bacterial food in a final concentration of $1 \mathrm{mM} .0 .3 \%$ DMSO served as vehicle control.

\section{RNA preparation}

For preparation of total RNA, $48 \mathrm{~h}$ nematode cultures from two $94 \mathrm{~mm}$ NGM agar plates were washed off with M9 buffer (18). Nematodes were washed two times with M9 buffer and collected through gravity-mediated down-settling. Isolation of total RNA was performed with the 'Total RNA isolation kit' (Macherey-Nagel, Germany), including removal of the genomic DNA by DNase digestion. Before, the worm pellet (about $100 \mathrm{mg}$ fresh weight) was resuspended in two volumes of the kit's lysis buffer, supplemented with one volume of glass beads $(\varnothing 0.5 \mathrm{~mm}$; Braun-Melsungen, Germany) and mechanically homogenized for $2 \times 2$ min using a SpeedMill P12 from Analytik Jena (Germany). This step was found to markedly enhance the RNA yield. All further steps were done exactly following the protocol of the kit supplier.

\section{Statistical analysis}

The pharynx activity assay datasets were analyzed by one way analysis of variance (ANOVA) to test for significant differences between treatments followed by the Bonferroni test to identify treatments, that were significantly different from the control. All statistical tests were performed using Sigma Stat 3.5 (SPSS ${ }^{\circledR}$, USA). The 'Enzyme Kinetics Module' of SigmaPlot 7 (SPSS, USA) was used for data analysis according to the Michaelis-Menten-Kinetics.

\section{RESULTS}

\section{Cloning and heterologous expression of CYP33E2}

The CYP33E2 cDNA amplified from $C$. elegans $\mathrm{N} 2$ showed $100 \%$ identity with the corresponding mRNA (GenBank ${ }^{\circledR}$ RefSeq NM_069069) and WormBase ${ }^{\circledR}$ sequences (F42A9.5). Heterologous expression of the CYP33E2 cDNA was achieved in a baculovirus/Sf9 insect cell system. Microsomes isolated from insect cells transfected with the recombinant CYP33E2baculovirus showed well-shaped reduced carbon monoxide spectra with a Soret peak at $450 \mathrm{~nm}$ indicating that the majority of the P450 enzyme expressed retained haem thiolate co-ordination in the ferrous-CO complex. Moreover, there was no evidence for any substantial amount of a P420 form, which could indicate an inactive form of the enzyme in the resting state (Supplementary Fig. S1, available at http://www.BiochemJ.org/bj/..). In contrast, control microsomes isolated after transfection with an empty baculovirus were free of any spectrally detectable CYP protein. Successful CYP33E2 expression was also revealed in SDS-PAGE by the presence of a prominent $53 \mathrm{kDa}$ protein band that occurred only in the microsomal samples of cells infected with the recombinant CYP33E2-baculovirus (data not shown). Maximal 
expression levels of $150 \mathrm{nmol}$ CYP33E2 per litre of cell culture were obtained $48 \mathrm{~h}$ post infection. Coexpression of CYP33E2 and hCPR was achieved by co-infection of the Sf9 cells with the corresponding recombinant baculoviruses. The microsomes obtained from the coinfected cell cultures and used for the subsequent metabolic studies contained $0.3 \mathrm{nmol}$ spectrally active CYP33E2/mg protein and had a CYP:hCPR ratio of about 5:1.

\section{Metabolism of LA by recombinant CYP33E2}

We first used LA as a test substrate to confirm the successful reconstitution of a microsomal monooxygenase system consisting of CYP33E2 and hCPR. As shown in Fig. 1, LA was efficiently metabolized by the complete system in the presence of NADPH. No product formation occurred omitting NADPH or using microsomes lacking CYP33E2, hCPR or both of these components.

The main products of CYP33E2 catalyzed LA conversion were 11- and 12-hydroxylauric acid (11-OH- and 12-OH-LA) representing nearly $90 \%$ of the total product (Fig. $1 \mathrm{~A}$ and Table 1). 11-OH- and 12-OH-LA were formed in a ratio of 5.3:1. Dodecanedicarboxylic acid, potentially co-migrating with 11-OH-LA in RP-HPLC, was not formed as proved after converting the reaction products into the corresponding methyl-esters (Fig. 1B). Minor products, indicated as LX1 and LX2 in Fig. 1, could not be unequivocally identified. In LC-MS, LX2 showed a molecular ion at $\mathrm{m} / \mathrm{z} 199$, suggesting that this $\left[1-{ }^{14} \mathrm{C}\right]$-labelled product originated from LA dehydrogenation.

Kinetic analysis showed that the CYP33E2/hCPR monooxygenase system hydroxylated LA with a $V_{\max }$ value of $5.6 \mathrm{nmol} / \mathrm{nmol} / \mathrm{min}$ and an apparent $K_{\mathrm{m}}$ value of $28 \mu \mathrm{M}$ (Tab. 1). The relative ratio of $11-\mathrm{OH}-/ 12-\mathrm{OH}-\mathrm{LA}$ production was independent of the substrate concentration and the kinetic parameters refer to the total formation of both primary products.

\section{Metabolism of AA by recombinant CYP33E2}

AA was metabolized by CYP33E2 to a complex product pattern that consisted after long-term incubation (30 min at a $20 \mu \mathrm{M}$ AA concentration) of primary hydroxy- and epoxy-metabolites as well as a series of secondary and unknown metabolites (Fig. 2A). Like LA, AA was only metabolized in the presence of NADPH and none of the metabolites occurred in incubations with control microsomes lacking CYP33E2.

The main primary hydroxy-metabolites produced by CYP33E2 co-migrated with 19-/20hydroxyeicosatetraenoic acid (19-/20-HETE) in RP-HPLC (Fig. 2A). Further resolution of this product peak by NP-HPLC revealed that CYP33E2 produced 19-HETE and 20-HETE in a ratio of about 13:1 (Fig. 2B). In LC-MS analysis, both $\left[1-{ }^{14} \mathrm{C}\right]$-labelled metabolites showed the expected molecular ions at $\mathrm{m} / \mathrm{z} 321$. Further confirming the identity of the main hydroxymetabolite, $\mathrm{CID}$ yielded product ions at $\mathrm{m} / \mathrm{z} 303$ (loss of $\mathrm{H}_{2} \mathrm{O}$ ), 275 (loss of $\mathrm{CO}_{2}$ ), and 231 (combined loss of $\mathrm{CO}_{2}$ and $\mathrm{CH}_{3} \mathrm{CH}_{2} \mathrm{OH}$ ) as characteristic for 19-HETE.

The primary epoxy-metabolites produced by CYP33E2 included all four regioisomeric epoxyeicosatrienoic acids (EETs). 14,15-EET, 11,12-EET and 8,9-EET were produced in a ratio of about 2.8:2.2:1. In addition, low amounts of the highly unstable 5,6-EET (about $5 \%$ of total epoxygenase product) were detectable (Fig. 2A, Table 2).

A series of minor reaction products eluted between 19-/20-HETE and 14,15-EET in RPHPLC (Fig. 2A and Table 2). Typically this region contains the monohydroxy-derivatives of AA originating from CYP-catalyzed subterminal and mid-chain oxidations. Most of the products indeed showed corresponding molecular ions at m/z 321 in LC-MS (Table 2). Among these 
compounds, the product eluting directly in front of 19-/20-HETE displayed an informative CID spectrum with fragment ions at $\mathrm{m} / \mathrm{z} 303$ (loss of $\mathrm{H}_{2} \mathrm{O}$ ) and 263 (loss of $\mathrm{CH}_{3} \mathrm{CH}_{2} \mathrm{CH}_{2} \mathrm{OH}$ ) indicating the presence of 18-HETE. In addition, there were two minor products showing molecular ions at m/z 319 suggesting further oxidation of hydroxy- to keto-derivatives (Table 2). The uncertain metabolite "AX5" eluting $3.5 \mathrm{~min}$ before AA (compare Fig. 2A) showed a molecular ion at $\mathrm{m} / \mathrm{z} 303$ and thus most probably represented a dehydrogenation product of AA.

Secondary products, whose concentrations strongly increased upon prolonged reaction times, eluted between 8.6 and $10 \mathrm{~min}$ in RP-HPLC (Fig. 2A). LC-MS revealed the presence of multiple compounds with a common molecular ion at $\mathrm{m} / \mathrm{z} 337$ indicating that these metabolites comprised dioxygenated products. Most likely candidates are regioisomeric hydroxyepoxyeicosatrienoic acids (HEETs) formed by secondary epoxidation of 19- and 20HETE or by secondary hydroxylation of EETs. Confirming this assumption, 19-/20-HETE was converted by CYP33E2 to products with retention times identical to the secondary AA metabolites (data not shown). Dihydroxyeicosatrienoic acids (DHETs), the hydrolysis products of EETs, elute between 12.5 and $14.5 \mathrm{~min}$ from RP-HPLC and were not formed under the conditions used.

During short-term incubations ( $5 \mathrm{~min}$ ), the secondary products described above were not formed and the relative ratio of primary hydroxy- and epoxy-metabolites was $1.4: 1$, independent of the substrate concentration. Formation of total primary hydroxy- and epoxy-metabolites from AA followed Michaelis-Menten kinetics with an apparent $K_{\mathrm{m}}$ value of about $47 \mu \mathrm{M}$ and a $V_{\max }$ value of $6 \mathrm{nmol} / \mathrm{nmol} / \mathrm{min}$ (Tab. 2).

\section{Metabolism of EPA by recombinant CYP33E2}

At a substrate concentration of $20 \mu \mathrm{M}$, CYP33E2 metabolized EPA with an almost two-fold higher rate than AA. The complex product pattern obtained after long-term incubation (30 min) consisted predominantly of monohydroxy- and monoepoxy-derivatives (Fig. 3A and Table 3). Based on co-migration with authentic standard compounds, the primary hydroxy-metabolites detectable in RP-HPLC at $\mathrm{R}_{\mathrm{t}}=14.5 \mathrm{~min}$ were 19 - and/or 20-hydroxyeicosapentaenoic acid (19/20-HEPE); Fig. 3A. Further resolution by NP-HPLC demonstrated that this fraction consisted almost exclusively of 19-HEPE, whereas 20-HEPE was not detectable at all (Fig. 3B). In LC-MS, the major metabolite isolated from NP-HPLC showed a molecular ion at m/z 319 and CIDinduced fragment ions at m/z 301 (loss of $\mathrm{H}_{2} \mathrm{O}$ ), 273 (loss of ${ }^{14} \mathrm{CO}_{2}$ ), and 227 (combined loss of ${ }^{14} \mathrm{CO}_{2}$ and $\left.\mathrm{CH}_{3} \mathrm{CH}_{2} \mathrm{OH}\right)$ as characteristic for 19-HEPE.

17,18-epoxyeicosatetraenoic acid (17,18-EEQ) represented almost $70 \%$ of the total epoxy-metabolites produced by CYP33E2 from EPA (Fig. 3A and Table 3). Chiral-phase HPLC revealed a moderate stereoselectivity of CYP33E2 in favour of producing the R,S-enantiomer of 17,18-EEQ (Fig. 3C). Other regioisomeric EEQs migrating largely unresolved in RP-HPLC were resolved into 14,15,11,12- and 8,9-EEQ by means of NP-HPLC and comprised about 9, 16 and $8 \%$ of the total epoxy-metabolites (Fig. 3D and Table 3 ).

Among the minor products with uncertain identity (compare Fig. 3A), EX1 and EX2 showed molecular ions at $\mathrm{m} / \mathrm{z} 335$ indicating the incorporation of two oxygen atoms into the [1$\left.{ }^{14} \mathrm{C}\right]$-EPA substrate. EX1 may represent a mixture of regioisomeric hydroxyepoxy-metabolites formed as secondary products similar as discussed above for the HEETs produced from AA. The retention time of EX2 was slightly higher than that of the vicinal diols derived from the EEQs (e.g. the 17,18-diol elutes at $9.7 \mathrm{~min}$ ) leaving diepoxides as the most likely candidates. The minor products eluting between 19-HEPE and 17,18-EEQ showed molecular ions at $\mathrm{m} / \mathrm{z} 319$ 
indicating the formation of subterminal and mid-chain HEPEs. LC-MS analysis of EX3 gave a single product with $\mathrm{m} / \mathrm{z} 301$ suggesting the abstraction of two H-atoms from EPA. Neither, EX3 nor any other of the minor and main products described above were produced in control experiments, where either NADPH was omitted or microsomes lacking CYP33E2 were used.

After short-term incubations as used for kinetic analysis ( $5 \mathrm{~min}), \mathrm{EX} 1$ and EX2 were not detectable and the ratio of primary hydroxy- and epoxy-metabolites was $0.6: 1$, independent of the substrate concentration. Formation of total primary hydroxy- and epoxy-metabolites from EPA followed the Michaelis-Menten kinetics with an apparent $K_{\mathrm{m}}$ value of about $67 \mu \mathrm{M}$ and a $V_{\max }$ value of $13 \mathrm{nmol} / \mathrm{nmol} / \mathrm{min}$ (Tab. 3).

\section{The endogenous CYP-eicosanoid profile of $C$. elegans}

To prove the in vivo formation of CYP-dependent eicosanoids, we analyzed C. elegans cultures by LC-MS/MS for the presence of EPA- and AA-derived monohydroxy- and monoepoxymetabolites. As summarized in Fig. 4, wild type worms contained a set of well-detectable metabolites that was clearly dominated by the epoxygenase and hydroxylase products of EPA. The total EPA/AA metabolite ratio was about 95:5 (for the complete data set see Supplementary Table S1, available at http://www.BiochemJ.org/bj/..). EPA-derived epoxy- and hydroxymetabolites occurred in a ratio of about 4:1. Among the individual regioisomeric metabolites, 17,18-EEQ $(791 \pm 229 \mathrm{ng} / \mathrm{g}$; mean $\pm \mathrm{SD}, \mathrm{n}=3)$ and 19-HEPE $(257 \pm 112 \mathrm{ng} / \mathrm{g})$ represented the predominant epoxygenase and hydroxylase products, respectively. In addition to the epoxides, we also detected significant amounts of the corresponding diols, indicating that the epoxides were further metabolized by epoxide hydrolases expressed in C. elegans (Table S1, available at http://www.BiochemJ.org/bj/..). Compared to the wild-type strain, the fat-1(wa9) mutant strain, which is deficient in n-3 PUFA biosynthesis, showed an almost complete shift from EPA- to AA-derived metabolites (Fig. 4). The fat- 1 strain contained large amounts of 19-HETE (303 \pm 72 $\mathrm{ng} / \mathrm{g})$ and 20-HETE $(211 \pm 33 \mathrm{ng} / \mathrm{g})$ that were about 8 - and 15 -fold higher compared to the wildtype strain. Similarly, the total amount of EETs was increased almost 16-fold. In contrast, the content of all CYP-dependent EPA metabolites was strongly reduced. 19- and 20-HEPE were undetectable and the total amount of EEQs was about 50-fold lower compared to the wild-type strain. The fat-3(wa22) mutant strain, that produces neither EPA nor AA, contained only trace amounts of all the EPA- and AA-derived metabolites.

\section{In vivo localization of CYP33E2.}

To identify the expression sites of CYP33E2 in C. elegans, we used worms stably transfected with a $p C Y P 33 E 2: \because G F P$ reporter construct. As shown in Fig. 5A, CYP33E2 promoter-driven expression of the green fluorescent protein occurred exclusively in the pharynx and, not visible in each individual, in the pharyngeal-intestinal valve of the nematodes. This type of strong, pharynx-restricted expression was observed throughout larval development and in adult worms. Expression was most prominent in the pharyngeal pro- and metacarpus (Fig. 5B). Confocal imaging suggested marginal, muscle, and/or epithelial cells as the major expression sites of the pCYP33E2::GFP construct within the pharynx (Fig. 5C). Radially, only marginal cell types are continuously organized with three-fold symmetry around the pharyngeal lumen. Imaginary cross sections derived from confocal imaging series of the pro- and metacorpus (Fig. 6B) indicated that the GFP reporter was expressed in the three marginal mc1 cells, but not in the pm3 and pm4 muscle cells, which should be visible in a cross section rather as six-fold divided structure (Fig. 6C). A further labelling of the mc2 and mc3 marginal cells in the isthmus and terminal bulb 
becomes visible in Fig. 5C (see the two lower fluorescence images). Marginal cells have characteristics of epithelia and are coupled to pharyngeal muscles via gap junctions and large interlocking extensions $(29,30)$. The finger-like fluorescent structures shown in Fig. 6A obviously represent these interlocking extensions that hold marginal cells to muscles. Furthermore, an expression of $p C Y P 33 E 2::$ GFP also in the epithelial e1, e2, and e 3 cells seems most likely, as shown both by fluorescent cell structures around the buccal cavity (Fig. 5C, see the arrows in the two upper fluorescence images, similar structures are also visible in Fig. 6A) and by further fluorescence additionally to the three-fold symmetry of marginal cells appearing in the second cross section of Fig. 6B. The latter might also correspond to pm2 muscle cells (compare Fig. 6C).

\section{Lack of LC-PUFAs, CYP33E2 gene silencing and CYP inhibitors decrease the pharyngeal pumping frequency}

The pharynx of $C$. elegans pumps continuously and we measured an average frequency of $256 \pm 10$ contractions per min in wild-type worms at the third day of adulthood (Fig. 7A). Fat3 (wa22) mutant worms cultured in parallel showed a significantly reduced pumping rate of $199 \pm 13$ (mean \pm SEM from 30 individual worms per group; $p<0.001$ versus wild-type control) that was restored almost to the wild-type level by AA/EPA-supplementation (Fig. 7A). RNAi feeding efficiently reduced the CYP33E2 mRNA level. About $30 \%$ of the CYP33E2 mRNA remained compared to the empty vector feeding control, as indicated by a mean delay of 1.72 cycles in CYP33E2 specific qRT-PCR and unchanged amplification of the reference act-1 mRNA (Fig. 7B). Silencing of CYP33E2 expression resulted in a decrease of the pumping rate to $226 \pm 10$ ( $p<0.01$ versus empty vector feeding control); Fig. 7A. Similarly, worm cultures pretreated with 17-ODYA or PPOH for $24 \mathrm{~h}$ displayed significantly reduced pumping rates of $225 \pm 14$ and $226 \pm 13$ (each $\mathrm{p}<0.05$ versus vehicle control); Fig. 7A.

\section{DISCUSSION}

The present study revealed that CYP33E2 is specifically expressed in the pharynx of C. elegans and demonstrates that this CYP isoform functions as an epoxygenase and $\omega-1$ hydroxylase of EPA and AA. Moreover, our results suggest a role of CYP33E2 in the regulation of pharyngeal activity.

CYP33E2 shares with other microsomal CYP isoforms a series of characteristic sequence elements including the $\mathrm{N}$-terminal signal anchor-, central helix I- and C-terminal haem binding regions. In particular, CYP33E2 shows pronounced amino acid sequence homology to mammalian AA epoxygenases belonging to the CYP2C and CYP2J subfamilies (14), for an alignment with human CYP2J2 see Supplementary Fig. S2 (available at http://www.BiochemJ.org/bj/..). These structural similarities are now complemented by our functional studies showing that CYP33E2 can be reconstituted with the human NADPH-CYP reductase to an active microsomal monooxygenase system that metabolizes EPA and AA. The metabolite pattern produced by CYP33E2 closely resembles that of CYP2J2, an epoxygenase highly expressed in the human heart $(26,34,35)$. Like CYP2J2, CYP33E2 attacks all four double bonds of AA to produce regioisomeric EETs and predominantly expoxidizes the $\omega-3$ double bond to produce 17,18-EEQ as the main metabolite from EPA. Moreover, both CYP2J2 and CYP33E2 hydroxylate AA and EPA with a high regioselectivity in favour of producing 19- 
HETE and 19-HEPE, respectively. Also LA was mainly hydroxylated at the $\omega-1$ position. These enzymatic features largely exclude a role of CYP33E2 in fatty acid degradation and rather point to a role of this enzyme in the production of lipid mediators, similar to that increasingly recognized for its mammalian counterparts $(10,11,36,37)$.

EPA- and AA-derived epoxy- and hydroxy-metabolites were clearly detectable as endogenous constituents in cultured wild type worms indicating that these metabolites are also formed under in vivo conditions. The endogenous CYP-eicosanoid profile showed a remarkable similarity to the metabolite pattern produced by recombinant CYP33E2. Both in vivo and in vitro, 17,18-EEQ and 19-HEPE were the main metabolites derived from EPA. Moreover, the similarity extends to the pattern of regioisomeric EETs produced from AA. However, we also observed some major differences. CYP33E2 produced 19- and 20-HETE in a ratio of 13:1, whereas the cultured worms contained these metabolites in almost equal amounts. Furthermore, 20-HEPE, a metabolite not produced by CYP33E2, was clearly present as an endogenous constituent. This comparison suggests a major role of CYP33E2 in the formation of EPA and AA metabolites in $C$. elegans, but also indicates that further CYP isoforms contribute to the endogenous metabolite pattern. In particular, the expression of at least one further CYP isoform has to be assumed that, unlike CYP33E2, predominantly functions as $\omega$-hydroxylase. We observed huge differences comparing the endogenous CYP-eicosanoid profile of the wild type strain with that of the fat-1 and fat-3 mutant strains. The wild type strain contained predominantly EPA-derived metabolites, the fat-1 strain expressed almost exclusively AA-derived metabolites, and the fat-3 strain was essentially devoid of any EPA- and AA-derived metabolites. These differences in endogenous metabolite formation perfectly fit to the relative bioavailability of the precursor fatty acids: EPA is the predominant long-chain PUFA in the wild-type strain (14), the fat-1 strain is unable to produce EPA, and the fat-3 strain is deficient in the biosynthesis of both EPA and AA. Considering the substrate specificity of CYP33E2, this enzyme presumably contributed not only to the formation of EPA metabolites in the wild-type strain but also of the AA metabolites in the fat- 1 strain. In analogy to these findings, the endogenous CYP-eicosanoid profile of mammalian tissues also largely depends on the relative bioavailability of the various LC-PUFAs that may serve as alternative CYP substrates $(23,38)$.

The pharynx of $C$. elegans is a rhythmically active muscular pump that sucks nutrients (bacteria) and passes them to the intestine of the animal $(39,40)$, pharyngeal pumping is mainly excited by the motor neurons MC and M3 (29). Our results indicate that CYP33E2 is predominantly expressed within the three marginal mcl cells that extend from the most anterior muscle cell in the procorpus down to the nerve ring in the metacorpus of the pharynx. Weak but significant expression was also found in the subsequent isthmus and terminal bulb region, where CYP33E2 is mainly localized in the marginal mc2 and mc3 cells. In each of these three segments, the marginal cells are coupled to pharyngeal muscle cells via gap junctions. Marginal cells are hypothesized to function as relay stations to synchronously transmit signals from motor neurons to the muscle cells and thus to support coordinated contraction of the pharynx (39). Marginal cells might be also involved in generating the spontaneous rhythmic activity of the pharynx that remains even after complete ablation of the pharyngeal nervous system $(31,40)$.

Our study shows that RNAi-mediated silencing of CYP33E2 expression as well as pharmacological inhibition of CYP activity causes a moderate but significant decrease of the pharyngeal pumping rate. Reduced pharyngeal activity may result in caloric restriction which in turn can be associated with increased lifespan as demonstrated by a series of the so-called "eatmutants" of C. elegans (41-43). Indeed, there is one report showing that CYP33E2 belongs to a 
list of genes whose silencing results in a longevity phenotype. Specifically, RNAi mediated gene silencing of CYP33E2 increased the mean lifespan of $C$. elegans by $18 \%$ (44). Thus, CYP33E2 might play an important role in the regulation of pharyngeal activity throughout the whole lifetime of the animal.

The degree of pharyngeal activity inhibition by CYP33E2 gene silencing or pharmacological CYP inhibition was similar to that observed with the fat-3(wa22) mutant. Since fat-3 mutants are unable to produce EPA and AA and CYP33E2 metabolizes these LC-PUFAs, it is tempting to speculate that the epoxy- and hydroxy- derivatives of EPA and AA may serve as mediators in the regulation of pharyngeal activity. All our data refer to worms that had full access to bacterial food and were thus pumping with almost maximal and constant rates. This may explain the rather moderate effects of LC-PUFA or CYP33E2 deficiency and it remains to future studies to define the physiological context and significance of CYP-eicosanoid formation and action for the regulation of pharyngeal activity. In analogy to the formation of CYPeicosanoids in mammalian systems, it can be expected that CYP33E2 becomes active in response to extracellular signals that trigger the activation of phospholipases A2 and thus make free AA and/or EPA accessible to the enzyme. Potential candidates may be among the factors that regulate the feeding behaviour of $C$. elegans such as serotonin, acetylcholine or glutamate (40). Another important open question concerns the identity of the final effectors of CYP-eicosanoid action. In mammals, EETs and EEQs produced in endothelial cells regulate vascular contractility by modulating the activity of large conductance- and ATP-sensitive potassium channels in the underlaying vascular smooth muscle cells $(39,45)$. In cardiomyocytes, L-type calcium channels and ATP-sensitive potassium channels are the main effectors of EET and EEQ action (46,47). In C. elegans, leading candidates may be ion channels that shape or modulate the action potential of the pharyngeal muscle cells such as the L-type calcium channel EGL-19 and the potassium channel EXP-2 $(48,49)$. A precedent to think about alternative mechanisms is provided by some vascular beds, where EETs activate endothelial transient receptor potential channels causing membrane hyperpolarization that is transferred to the smooth muscle via gap junctions (50).

Numerous studies revealed functional similarities between the $C$. elegans pharynx and the vertebrate heart that are discussed to reflect either true orthology or convergent evolution $(39,48)$. The present study indicates that the apparent homologies may extend to the role of CYPeicosanoids in the regulation of myogenic activity.

\section{ACKNOWLEDGEMENTS}

We thank the Caenorhabditis Genetics Centre (CGC), which is funded by the National Institutes of Health National Centre for Research Resources, for the supply of N2 and fat-3(wa22). We are grateful to Christel Andrée and Ramona Zummach (both MDC, Germany) for excellent technical support and advice during the in vitro assays and the HPLC experiments.

\section{FUNDING}

W.H.S. and R.M. were supported by grants (SCHU 822/5-1 and STE 673/16-1) from the German Research Foundation (DFG). 


\section{REFERENCES}

1 Watts, J.L. and Browse, J. (2002) Genetic dissection of polyunsaturated fatty acid synthesis in Caenorhabditis elegans. Proc. Natl. Acad. Sci. U.S.A. 99, 5854-5859

2 Wallis, J.G., Watts, J.L. and Browse, J. (2002) Polyunsaturated fatty acid synthesis: what will they think of next? Trends Biochem. Sci. 27, 467-473

3 Kahn-Kirby, A.H., Dantzker, J.L., Apicella, A.J., Schafer, W.R., Browse, J., Bargmann, C.I. and Watts, J.L. (2004) Specific polyunsaturated fatty acids drive TRPV-dependent sensory signaling in vivo. Cell 119, 889-900

4 Watts, J.L., Phillips, E., Griffing, K.R. and Browse, J. (2003) Deficiencies in C20 polyunsaturated fatty acids cause behavioral and developmental defects in Caenorhabditis elegans fat-3 mutants. Genetics 163, 581-589

5 Kubagawa, H.M., Watts, J.L., Corrigan, C., Edmonds, J.W., Sztul, E., Browse, J. and Miller, M.A. (2006) Oocyte signals derived from polyunsaturated fatty acids control sperm recruitment in vivo. Nat. Cell Biol. 8, 1143-1148

6 Funk, C.D. (2001) Prostaglandins and leukotrienes: advances in eicosanoid biology. Science 294, 1871-1875

7 Lesa, G.M., Hall, D.H., Clandinin, M.T., Rudolph, C., Jorgensen, E.M. and Schiavo, G. (2003) Long chain polyunsaturated fatty acids are required for efficient neurotransmission in C. elegans. J. Cell Sci. 116, 4965-4975

8 Hillyard, S.L. and German, J.B. (2009) Quantitative lipid analysis and life span of the fat-3 mutant of Caenorhabditis elegans. J. Agric. Food Chem. 57, 3389-3396

9 McGiff, J.C. and Quilley, J. (1999) 20-HETE and the kidney: resolution of old problems and new beginnings. Am. J. Physiol. 277, R607-623

10 Capdevila, J.H. and Falck, J.R. (2002) Biochemical and molecular properties of the cytochrome P450 arachidonic acid monooxygenases. Prostaglandins Other Lipid Mediat. 68-69, 325-344

11 Roman, R.J. (2002) P-450 metabolites of arachidonic acid in the control of cardiovascular function. Physiol. Rev. 82, 131-185

12 Arnold, C., Konkel, A., Fischer, R. and Schunck, W.H. (2010) Cytochrome P450-dependent metabolism of omega- 6 and omega- 3 long-chain polyunsaturated fatty acids. Pharmacol. Rep. 62, 536-547

13 Nelson, D.R., Zeldin, D.C., Hoffman, S.M., Maltais, L.J., Wain, H.M. and Nebert, D.W. (2004) Comparison of cytochrome P450 (CYP) genes from the mouse and human genomes, including nomenclature recommendations for genes, pseudogenes and alternative-splice variants. Pharmacogenetics 14, 1-18

14 Kulas, J., Schmidt, C., Rothe, M., Schunck, W.H. and Menzel, R. (2008) Cytochrome P450dependent metabolism of eicosapentaenoic acid in the nematode Caenorhabditis elegans. Arch. Biochem. Biophys. 472, 65-75

15 Schierenberg, E., Miwa, J. and von Ehrenstein, G. (1980) Cell lineages and developmental defects of temperature-sensitive embryonic arrest mutants in Caenorhabditis elegans. Dev. Biol. 76, 141-159

16 Rappleye, C.A., Tagawa, A., Le Bot, N., Ahringer, J. and Aroian, R.V. (2003) Involvement of fatty acid pathways and cortical interaction of the pronuclear complex in Caenorhabditis elegans embryonic polarity. BMC Dev. Biol. 3, 8 
17 Harris, T.R., Aronov, P.A., Jones, P.D., Tanaka, H., Arand, M. and Hammock, B.D. (2008) Identification of two epoxide hydrolases in Caenorhabditis elegans that metabolize mammalian lipid signaling molecules. Arch. Biochem. Biophys. 472, 139-149.

18 Brenner, S. (1974) The genetics of Caenorhabditis elegans. Genetics 77, 71-94

19 Schwarz, D., Kisselev, P., Cascorbi, I., Schunck. W.H. and Roots, I. (2001) Differential metabolism of benzo[a]pyrene and benzo[a]pyrene-7,8-dihydrodiol by human CYP1A1 variants. Carcinogenesis 22, 453-459

20 Lowry, O.H., Rosebrough, N.J., Farr, A.L. and Randall, R.J. (1951) Protein measurement with the Folin phenol reagent. J. Biol. Chem. 193, 265-275

21 Omura, T. and Sato, R. (1964) The Carbon Monoxide-binding Pigment of Liver Microsomes. J. Biol. Chem. 239, 2379-2385

22 Yasukochi, Y. and Masters, B.S. (1976) Some properties of a detergent-solubilized NADPH-cytochrome $c$ (cytochrome P-450) reductase purified by biospecific affinity chromatography. J. Biol. Chem. 251, 5337-5344

23 Arnold, C., Markovic, M., Blossey, K., Wallukat, G., Fischer, R., Dechend, R., Konkel, A., von Schacky, C., Luft, F.C., Muller, D.N., Rothe, M. and Schunck, W.H. (2010) Arachidonic acid-metabolizing cytochrome P450 enzymes are targets of \{omega\}-3 fatty acids. J. Biol. Chem. 285, 32720-32733

24 Barbosa-Sicard, E., Markovic, M., Honeck, H., Christ, B., Muller, D.N. and Schunck, W.H. (2005) Eicosapentaenoic acid metabolism by cytochrome P450 enzymes of the CYP2C subfamily. Biochem. Biophys. Res. Commun. 329, 1275-1281

25 Muller, D.N., Schmidt, C., Barbosa-Sicard, E., Wellner, M., Gross, V., Hercule, H., Markovic, M., Honeck, H., Luft, F.C. and Schunck, W.H. (2007) Mouse Cyp4a isoforms: enzymatic properties, gender- and strain-specific expression, and role in renal 20hydroxyeicosatetraenoic acid formation. Biochem. J. 403, 109-118

26 Wilm, T., Demel, P., Koop, H. U., Schnabel, H. and Schnabel, R. (1999) Ballistic transformation of Caenorhabditis elegans. Gene 229, 31-35

27 Zou, A.P., Ma, Y.H., Sui, Z.H., Ortiz de Montellano P.R., Clark, J.E., Masters, B.S. and Roman. R.J. (1994) Effects of 17-octadecynoic acid, a suicide-substrate inhibitor of cytochrome P450 fatty acid omega-hydroxylase, on renal function in rats. J. Pharmacol. Exp. Ther. 268, 474-481

28 Wang, M.H., Brand-Schieber, E., Zand, B.A., Nguyen, X., Falck, J.R., Balu, N. and Schwartzman, M.L. (1998) Cytochrome P450-derived arachidonic acid metabolism in the rat kidney: characterization of selective inhibitors. J. Pharmacol. Exp. Ther. 284, 966-973

29 Albertson, D.G. and Thomson, J.N. (1976) The pharynx of Caenorhabditis elegans. Philos. Trans. R. Soc. Lond., B, Biol. Sci. 275, 299-325

30 Avery, D.G. and Thomas, J.H. (1997) Feeding and defecation. In C. elegans Volume II. Ed.s Riddle D.L., Blumenthal, T., Meyer B.J. and Priess J.R. Pp 679-716. Cold Spring Harbor Laboratory, Cold Spring Harbor, NY

31 Avery, L. and Horvitz, H. R. (1989) Pharyngeal pumping continues after laser killing of the pharyngeal nervous system of C. elegans. Neuron 3, 473-485

32 Raizen, D.M. and Avery, L. (1994) Electrical activity and behavior in the pharynx of Caenorhabditis elegans. Neuron 12, 483-495.

33 Altun, Z.F. and Hall, D.H. (2009) SW-Worm Viewer, Slice No. 19, 34 and 50. In WormAtlas. http://www.wormatlas.org/SW/SW.php 
34 Wu, S., Moomaw, C. R., Tomer, K. B., Falck, J. R. and Zeldin, D. C. (1996) Molecular cloning and expression of CYP2J2, a human cytochrome $\mathrm{P} 450$ arachidonic acid epoxygenase highly expressed in heart. J. Biol. Chem. 271, 3460-3468

35 Fer, M., Dreano, Y., Lucas, D., Corcos, L., Salaun, J. P., Berthou, F. and Amet, Y. (2008) Metabolism of eicosapentaenoic and docosahexaenoic acids by recombinant human cytochromes P450. Arch. Biochem. Biophys. 471, 116-125

36 Campbell, W. B. and Falck, J. R. (2007) Arachidonic acid metabolites as endotheliumderived hyperpolarizing factors. Hypertension 49, 590-596

37 Fleming, I. (2008) Vascular cytochrome p450 enzymes: physiology and pathophysiology. Trends Cardiovasc. Med. 18, 20-25

38 Konkel, A. and Schunck, W.H. (2011) Role of cytochrome P450 enzymes in the bioactivation of polyunsaturated fatty acids. Biochim. Biophys. Acta 1814, 210-222

39 Mango, S.E. (2007) The C. elegans pharynx: a model for organogenesis (January 22, 2007), WormBook, ed. The C. elegans Research Community, WormBook, doi/10.1895/wormbook.1.129.1, http://www.wormbook.org.

40 Franks, C. J., Holden-Dye, L., Bull, K., Luedtke, S. and Walker, R. J. (2006) Anatomy, physiology and pharmacology of Caenorhabditis elegans pharynx: a model to define gene function in a simple neural system. Invert. Neurosci. 6, 105-122

41 Avery, L. (1993) The genetics of feeding in Caenorhabditis elegans. Genetics 133, 897-917

42 Lakowski, B. and Hekimi, S. (1998) The genetics of caloric restriction in Caenorhabditis elegans. Proc Natl Acad Sci U S A 95, 13091-13096

43 Fontana, L., Partridge, L. and Longo, V. D. (2010) Extending healthy life span--from yeast to humans. Science 328, 321-326

44 Kim, Y. and Sun, H. (2007) Functional genomic approach to identify novel genes involved in the regulation of oxidative stress resistance and animal lifespan. Aging Cell 6, 489-503

45 Lu, T., Ye, D., Wang, X., Seubert, J. M., Graves, J. P., Bradbury, J. A., Zeldin, D. C. and Lee, H. C. (2006) Cardiac and vascular KATP channels in rats are activated by endogenous epoxyeicosatrienoic acids through different mechanisms. J. Physiol. 575, 627-644

46 Xiao, Y. F. (2007) Cyclic AMP-dependent modulation of cardiac L-type Ca2+ and transient outward $\mathrm{K}+$ channel activities by epoxyeicosatrienoic acids. Prostaglandins Other Lipid Mediat. 82, 11-18

47 Lu, T., VanRollins, M. and Lee, H. C. (2002) Stereospecific activation of cardiac ATPsensitive $\mathrm{K}(+)$ channels by epoxyeicosatrienoic acids: a structural determinant study. Mol. Pharmacol. 62, 1076-1083

48 Franks, C. J., Pemberton, D., Vinogradova, I., Cook, A., Walker, R. J. and Holden-Dye, L. (2002) Ionic basis of the resting membrane potential and action potential in the pharyngeal muscle of Caenorhabditis elegans. J. Neurophysiol. 87, 954-961

49 Shtonda, B. and Avery, L. (2005) CCA-1, EGL-19 and EXP-2 currents shape action potentials in the Caenorhabditis elegans pharynx. J. Exp. Biol. 208, 2177-2190

50 Campbell, W. B. and Fleming, I. (2010) Epoxyeicosatrienoic acids and endotheliumdependent responses. Pflugers Arch. 459, 881-895 
Table 1. Metabolism of LA by recombinant CYP33E2.

\begin{tabular}{|c|c|c|}
\hline \multicolumn{3}{|c|}{ Metabolite Pattern $^{\Gamma}$} \\
\hline Primary products & $\begin{array}{c}\text { Product } \\
\text { distribution }^{2}[\%]\end{array}$ & $\begin{array}{l}\text { Molecular mass }{ }^{3} \\
{[\mathrm{~g} / \mathrm{mol}]}\end{array}$ \\
\hline $\begin{array}{l}\text { 1. Hydroxy } \\
\text { products }\end{array}$ & $87.1 \pm 0.6$ & \\
\hline 11-OH-LA & $-83.7 \pm 0.1$ & 216 \\
\hline 12-OH-LA & $-16.3 \pm 0.5$ & 216 \\
\hline 2. Other products & $12.9 \pm 0.6$ & \\
\hline LX1 (unknown) & $-77.2 \pm 3.3$ & n.d. \\
\hline LX2 (dehydro-LA) & $-22.8 \pm 1.5$ & 198 \\
\hline \multicolumn{3}{|c|}{ Kinetic Parameters ${ }^{4}$} \\
\hline Lauric acid & $\begin{array}{c}K_{\mathbf{m}} \\
{[\mu \mathrm{M}]}\end{array}$ & $\begin{array}{c}V_{\max } \\
{[\mathrm{nmol} / \mathrm{nmol} / \mathrm{min}]}\end{array}$ \\
\hline CYP33E2 & $28.1 \pm 3.7$ & $5.6 \pm 0.3$ \\
\hline
\end{tabular}

${ }^{1}$ The metabolite pattern was analyzed by RP-HPLC as shown in Fig. 1. Data are mean \pm SD values from reactions performed with at least three independent microsomal preparations.

${ }^{2}$ Relative contribution of the metabolite class indicated to total product formation (bold numbers) and of the respective individual metabolites to a given metabolite class (regular numbers).

${ }^{3}$ Molecular mass was calculated from the $\mathrm{m} / \mathrm{z}$ values of the molecular ions (M-1) in LC-MS and adjusted to the products formed from unlabeled LA ( -2 for the presence of $\left[1-{ }^{14} \mathrm{C}\right]$ in the substrate used).

${ }^{4}$ The apparent $K_{\mathrm{m}}$ and $V_{\max }$ values were determined as described in Experimental Procedures and refer to the total LA hydroxylase activity of recombinant CYP33E2. 
Table 2. Metabolism of AA by recombinant CYP33E2.

\begin{tabular}{|c|c|c|}
\hline \multicolumn{3}{|c|}{ Metabolite Pattern } \\
\hline Primary products & $\begin{array}{c}\text { Product } \\
\text { distribution }^{2}[\%]\end{array}$ & $\begin{array}{c}\text { Molecular mass }^{3} \\
\text { [g/mol] }\end{array}$ \\
\hline 1. Epoxy products & $25.1 \pm 3.8$ & \\
\hline $14,15-\mathrm{EET}$ & $-43.3 \pm 1.5$ & 320 \\
\hline 11,12-EET & $-36.0 \pm 5.9$ & 320 \\
\hline $8,9-\mathrm{EET}$ & $-15.9 \pm 10.1$ & 320 \\
\hline 5,6-EET & $-4.8 \pm 1.1$ & 320 \\
\hline $\begin{array}{l}\text { 2. Hydroxy } \\
\text { products }\end{array}$ & $40.4 \pm 3.6$ & \\
\hline 20-HETE & $-4.7 \pm 0.4$ & 320 \\
\hline 19-HETE & $-62.3 \pm 3.2$ & 320 \\
\hline 18-HETE (AX2.1) & $-11.0 \pm 1,6$ & 320 \\
\hline HETE (AX2.2) & $-7.9 \pm 1.3$ & 320 \\
\hline HETE (AX3.1) & $-4.0 \pm 0.5$ & 320 \\
\hline Unknown (AX3.2) & $-1.5 \pm 0.4$ & 318 \\
\hline HETE (AX4.1) & $-2.1 \pm 0.1$ & 320 \\
\hline Unknown (AX4.2) & $-6.5 \pm 1.4$ & 318 \\
\hline $\begin{array}{l}\text { 3. Other products } \\
\text { AX5 (dehydro-AA) }\end{array}$ & $1.3 \pm 0.6$ & 302 \\
\hline $\begin{array}{c}\text { Secondary products } \\
\text { HEET }(A X 1)\end{array}$ & $20.5 \pm 2.0$ & 336 \\
\hline Unidentified & $\approx 13$ & \\
\hline \multicolumn{3}{|c|}{ Kinetic Parameters 4} \\
\hline Arachidonic acid & $\begin{array}{c}K_{\mathrm{m}} \\
{[\mu \mathrm{M}]}\end{array}$ & $\begin{array}{c}V_{\max } \\
{[\mathrm{nmol} / \mathrm{nmol} / \mathrm{min}]}\end{array}$ \\
\hline CYP33E2 & $46.8 \pm 6.1$ & $6.2 \pm 0.4$ \\
\hline
\end{tabular}

${ }^{1}$ The metabolite pattern was analyzed by RP-HPLC as shown in Fig. 2A. 19- and 20-HETE were resolved by NP-HPLC (Fig. 2B). Data are mean \pm SD values from reactions performed with at least three independent microsomal preparations.

${ }^{2}$ Relative contribution of the metabolite class indicated to total product formation (bold numbers) and of the respective individual metabolites to a given metabolite class (regular numbers).

${ }^{3}$ Molecular mass was calculated from the $\mathrm{m} / \mathrm{z}$ values of the molecular ions (M-1) in LC-MS and adjusted to the products formed from unlabeled AA $\left(-2\right.$ for the presence of $\left[1-{ }^{14} \mathrm{C}\right]$ in the substrate used).

${ }^{4}$ The apparent $K_{\mathrm{m}}$ and $V_{\max }$ values were determined using short-term incubation to avoid secondary product formation as described in Experimental Procedures and refer to the total AA hydroxylase and epoxygenase activity of recombinant CYP33E2. 
Table 3 Metabolism of EPA by recombinant CYP33E2.

\begin{tabular}{|c|c|c|}
\hline \multicolumn{3}{|c|}{ Metabolite Pattern $^{I}$} \\
\hline Primary products & $\begin{array}{c}\text { Product } \\
\text { distribution }^{2}[\%]\end{array}$ & $\begin{array}{c}\text { Molecular mass } \\
{[\mathrm{g} / \mathrm{mol}]}\end{array}$ \\
\hline 1. Epoxy products & $40.5 \pm 5.0$ & \\
\hline 17,18-EEQ & $-66.7 \pm 7.9$ & 318 \\
\hline 14,15-EEQ & $-9.5 \pm 0.1$ & 318 \\
\hline 11,12-EEQ & $-15.9 \pm 1.8$ & 318 \\
\hline 8,9-EEQ & $-7.9 \pm 2.5$ & 318 \\
\hline $\begin{array}{l}\text { 2. Hydroxy } \\
\text { products }\end{array}$ & $27.0 \pm 2.2$ & \\
\hline 19-HEPE & $-81.1 \pm 3.5$ & 318 \\
\hline HEPE (HX1) & $-2.6 \pm 1.2$ & 318 \\
\hline Subterminal HEPEs ${ }^{4}$ & $-16.3 \pm 3.4$ & 318 \\
\hline $\begin{array}{l}\text { 3. Other products } \\
\text { EX3 (dehydro-EPA) }\end{array}$ & $6.2 \pm 0.5$ & \\
\hline Secondary products & $16.9 \pm 1.7$ & \\
\hline HEEQ (EX1) & $-8.5 \pm 1.8$ & 334 \\
\hline DHEQ (EX2) & $-8.4 \pm 1.6$ & 334 \\
\hline Unidentified & $\approx 9$ & \\
\hline \multicolumn{3}{|c|}{ Kinetic Parameters 5} \\
\hline $\begin{array}{c}\text { Eicosapentaenoic } \\
\text { acid }\end{array}$ & $\begin{array}{c}K_{\mathrm{m}} \\
{[\mu \mathrm{M}]}\end{array}$ & $\begin{array}{c}V_{\max } \\
\underset{\mathrm{nmol}^{\prime} \cdot \mathrm{nmol}^{-1}}{\left.\min ^{-1}\right]}\end{array}$ \\
\hline CYP33E2 & $69.3 \pm 7.9$ & $13.1 \pm 0.9$ \\
\hline
\end{tabular}

${ }^{1}$ The metabolite pattern was analyzed by RP-HPLC as shown in Fig. 3A. 19- and 20-HEPE as well as regioisomeric EEQs were resolved by subsequent NP-HPLC (Figs. 3B and 3D). Data are mean \pm SD values from reactions performed with at least three independent microsomal preparations.

2 Relative contribution of the metabolite class indicated to total product formation (bold numbers) and of the respective individual metabolites to a given metabolite class (regular numbers).

${ }^{3}$ Molecular mass was calculated from the $\mathrm{m} / \mathrm{z}$ values of the molecular ions (M-1) in LC-MS and adjusted to the products formed from unlabeled EPA $\left(-2\right.$ for the presence of $\left[1-{ }^{14} \mathrm{C}\right]$ in the substrate used).

${ }^{4}$ Subterminal HEPESs refer to a set of probably four regioisomeric hydroxy metabolites presumably formed by allylic oxidation.

${ }^{5}$ The apparent $K_{\mathrm{m}}$ and $V_{\max }$ values were determined using short-term incubation to avoid secondary product formation as described in Experimental Procedures and refer to the total EPA hydroxylase and epoxygenase activity of recombinant CYP33E2. 


\section{FIGURE LEGENDS}

Figure 1 Metabolism of LA by recombinant CYP33E2. (A) Representative RP-HPLC chromatogram showing the metabolite pattern formed after incubating $4 \mathrm{nmol}$ LA with $50 \mathrm{pmol}$ of CYP33E2 in a total volume of $0.2 \mathrm{~mL}$ for $30 \mathrm{~min}$ at $25^{\circ} \mathrm{C}$ in the presence of $1 \mathrm{mM}$ NADPH (black line). No substrate conversion occurred in control samples, where NADPH was omitted (grey line) or microsomes devoid of CYP33E2 or hCPR were used. The two main metabolites co-migrated with authentic $11-\mathrm{OH}-\mathrm{LA}(\mathrm{Rt}=20.4 \mathrm{~min})$ and $12-\mathrm{OH}-\mathrm{LA}(\mathrm{Rt}=21.8 \mathrm{~min})$. Unknown products are designated as LX1 $(\mathrm{Rt}=21.1 \mathrm{~min})$ and $\mathrm{LX} 2(\mathrm{Rt}=40.7 \mathrm{~min})$. Compare Table 1 for further characterization of the metabolites. (B) Representative RP-HPLC chromatograms comparing the LA-derived metabolite patterns produced by CYP33E2 (black) and mouse Cyp4a12a (grey). The extracted samples were treated with diazomethane to generate the corresponding methyl esters (ME) that eluted at 32.9 (11-OH-LA-ME), 33,7 (LX1-ME), 34.3 (12-OH-LA-ME), 40.9 (DDDA-DME, dodecanedicarboxylic acid dimethylester), 42.6 (LX2$\mathrm{ME})$, and $43.9 \mathrm{~min}$ (LA-ME).

Figure 2 Metabolism of AA by recombinant CYP33E2. (A) Representative RP-HPLC chromatogram showing the metabolite pattern formed after incubating $40 \mathrm{nmol}$ AA with 500 pmol of CYP33E2 in a total volume of $2 \mathrm{~mL}$ for $30 \mathrm{~min}$ at $25^{\circ} \mathrm{C}$ in the presence of $1 \mathrm{mM}$ NADPH (black line). None of the metabolites were produced in control samples, where NADPH was omitted (grey line) or microsomes devoid of CYP33E2 or hCPR were used. Main metabolites co-migrated with authentic 19/20-HETE ( $\mathrm{Rt}=15.4 \mathrm{~min}$ ) and a set of regioisomeric monoepoxides at 23.5 (14,15-EET), 24.9 (11,12-EET), 25.3 (8,9-EET) and 25.9 min (5,6-EET). Metabolites with uncertain or unknown identity are marked (AX1...AX5). Compare Table 2 for further characterization of the metabolites. (B) Resolution of 19-HETE and 20-HETE by NPHPLC. Resolution of the product peak eluting at 15.4 min from RP-HPLC (compare panel A) revealed that CYP33E2 (black line) produced predominantly 19-HETE (Rt=14.5 min) whereas 20-HETE ( $\mathrm{Rt}=20 \mathrm{~min}$ ) was the main product in reactions samples run in parallel with mouse Cyp4a12a (grey line).

Figure 3 Metabolism of EPA by recombinant CYP33E2. (A) Representative RP-HPLC chromatogram showing the metabolite pattern formed after incubating $40 \mathrm{nmol}$ EPA with 500 pmol of CYP33E2 in a total volume of $2 \mathrm{~mL}$ for $30 \mathrm{~min}$ at $25^{\circ} \mathrm{C}$ in the presence of $1 \mathrm{mM}$ NADPH (black line). None of the metabolites were produced in control samples, where NADPH was omitted (grey line) or microsomes devoid of CYP33E2 or hCPR were used. Main metabolites co-migrated with authentic 19/20-HEPE (Rt=13.9 $\mathrm{min}), 17,18$-EEQ (Rt=19.5 min) and a set of other regioisomeric EEQs $(\mathrm{Rt}=21-23 \mathrm{~min})$. Minor metabolites included putative products of subterminal or mid-chain hydroxylations $(\mathrm{Rt}=14.5-18 \mathrm{~min})$ and three metabolites with uncertain identity designated EX1,2 and 3. Compare Table 3 for further characterization of the metabolites (B) Resolution of 19-HEPE and 20-HEPE by NP-HPLC. Resolution of the product peak eluting at 13.9 min from RP-HPLC (compare panel A) revealed that CYP33E2 (black line) produced exclusively 19-HEPE $(\mathrm{Rt}=13 \mathrm{~min}$ ) whereas both 19-HEPE and 20-HEPE $(\mathrm{Rt}=17 \mathrm{~min}$ ) were produced in reactions samples run in parallel with mouse Cyp4a12a (grey line). The minor product marked HX1 could not be identified. (C) Resolution of the 17,18-EEQ enantiomers by CP-HPLC. The product peak eluting at $19.5 \mathrm{~min}$ from RP-HPLC (compare panel A) was collected and resolved into the respective R,S- and S,R-enantiomers. (D) Resolution of 
regioisomeric EEQs by NP-HPLC. The metabolites eluting between 21 and 23 min from RPHPLC (compare panel A) were collected and resolved into 14,15-EEQ ( $\mathrm{Rt}=10.0 \mathrm{~min}$ ), 11,12EEQ (11.5 $\mathrm{min})$ and 8,9-EEQ (14.7 $\mathrm{min})$.

Figure 4 Endogenous CYP-eicosanoid profile of $\boldsymbol{C}$. elegans. Cultures of wild type nematodes as well as of fat-1 (wa9) and fat-3(wa22) mutant strains were harvested and the worms were analyzed by LC-MS/MS for the presence of AA- and EPA-derived metabolites. The bars showing the total amounts of hydroxy-metabolites derived from AA ("HETE") or EPA ("HEPE") represent the sum of the corresponding $\omega$ - and $(\omega-1)$-hydroxylase products. The bars designated as EET and EEQ show the total amounts as well as the regioisomeric composition of the epoxygenase products. Since the worms did not only contain a set of regioisomeric epoxides but also of the corresponding diols, the total epoxygenase products are given as the sum of the respective primary and secondary metabolites. Data are mean \pm SD from three independent cultures performed for each strain. For the complete data set see Supplementary Table S1 available at http://www.BiochemJ.org/bj/..).

Figure 5 CYP33E2 promoter driven GFP expression in $C$. elegans. Transgenic nematodes carrying the CYP32E2 promoter::GFP construct were transferred on an agarose pad mounted microscope slide and covered by a glass slip. (A) Gravid hermaphrodite and corresponding GFP fluorescence (B) Anatomy of the pharynx, schematic of a lateral view, anterior to the left. This figure is based on reconstructions made by different authors (30-32), which were originally derived from electron micrographs presented by Albertson and Thomson (29) (C) Shown are four representative confocal images representing the $13^{\text {th }}, 21^{\text {st }}, 30^{\text {th }}$, and $39^{\text {th }}$ horizontal section plane of total 81 images from worm's pharynx (left), the corresponding GFP fluorescence (centre), and a merge of the two pictures belonging together (right). The monitoring level runs top down as indicated. Expression was highest in the pro- and metacorpus and extended to the isthmus and terminal bulb region of the pharynx. The white arrows mark fluorescent cell structures which surround the buccal cavity and do probably correspond to epithelial cells.

Figure 6 Analysis of CYP33E2 promoter driven GFP expression in the pharyngeal pro- and metacorpus of $C$. elegans. (A) Shown is a pair of confocal images representing the $34^{\text {th }}$ horizontal section plane of total 51 images and the merge of both images. Note the fingerlike extensions which are suggested to hold the marginal cells to muscles as clearly visible in the central fluorescence image. (B) Shown are three derived vertical sections based on the 51 horizontal fluorescent images, the selected positions of imaginary sectioning are highlighted by white arrows in the figure above. (C) Shows the corresponding schemata of pharyngeal cross sections at the same position- white: pharyngeal lumen; blue: muscle cells (pm3, pm4), green: marginal cells ( $\mathrm{mc} 1)$, lilac: epithelial cells (e1-e3), yellow: muscle cells (pm2), gray: motor neurons, red: interneurons. These simplified schemata were derived from sections of the 'Slidable Worm' as presented by WormAtlas (33). Note that the three GFP expressing cells visible in B reflect the three-fold symmetry of the marginal mcl cells.

Figure 7 Pharyngeal pumping frequencies of $C$. elegans N2 as modulated by fat-3 mutation, CYP33E2 gene silencing and pharmacological inhibition of CYP activity. (A) The nematodes were monitored on the third day of adulthood. Shown are the beats per minute $(n=30-$ 
60 per group); for each individual animal, the pumping frequencies were counted in triplicate. Data are presented as box plot showing the 5th/95th percentile, solid line corresponds to the median, dashed line shows the mean, ${ }^{*} \mathrm{p}<0.05,{ }^{* *} \mathrm{p}<0.001$ (One way ANOVA). (B) The CYP33E2 mRNA level decreased in response to RNAi feeding. Total RNA was isolated from worm cultures fed with bacteria either containing the CYP33E2 RNAi vector or the empty control vector. Quantitative RT-PCR was performed using primer pairs specific for the amplification of CYP33E2 and act-1 (as housekeeper reference). Shown are the threshold cycles in dependency of the starting concentrations varied by a four-step 1:5 dilution series. Empty squares show the control, grey circles correspond with the CYP33E2 RNAi sample. E - estimated PCR efficiency. 
A

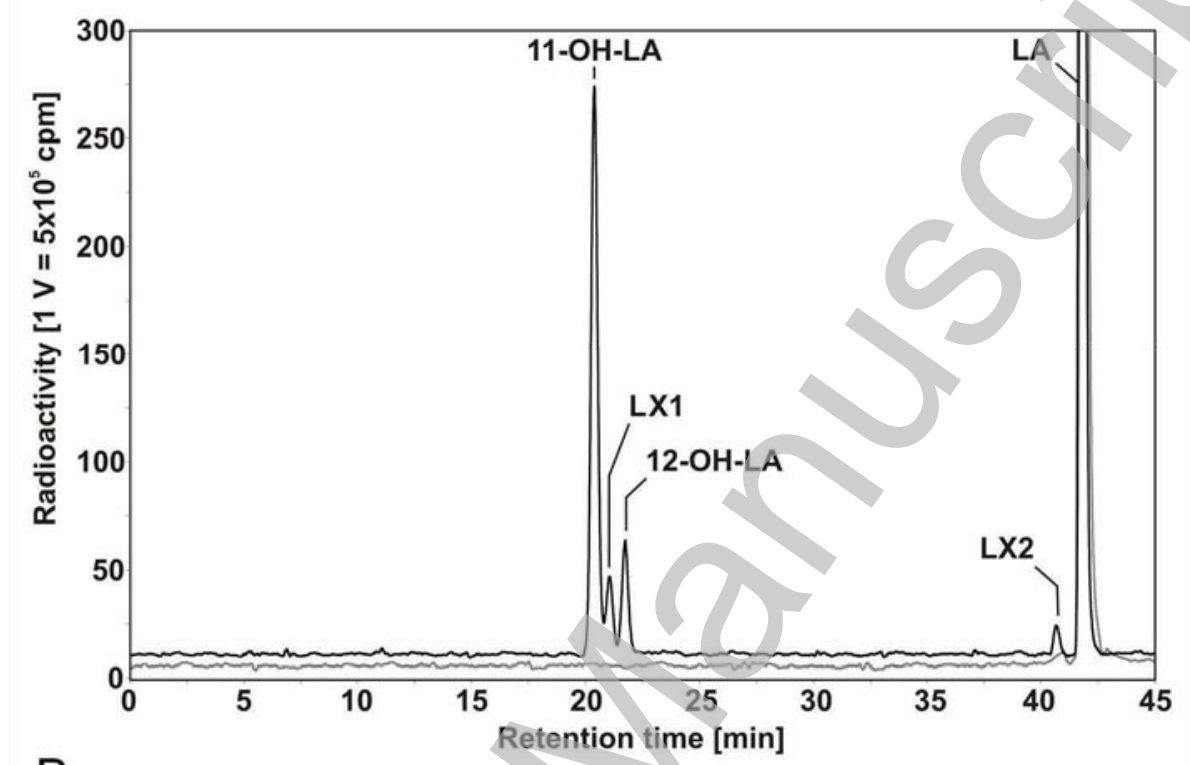

B

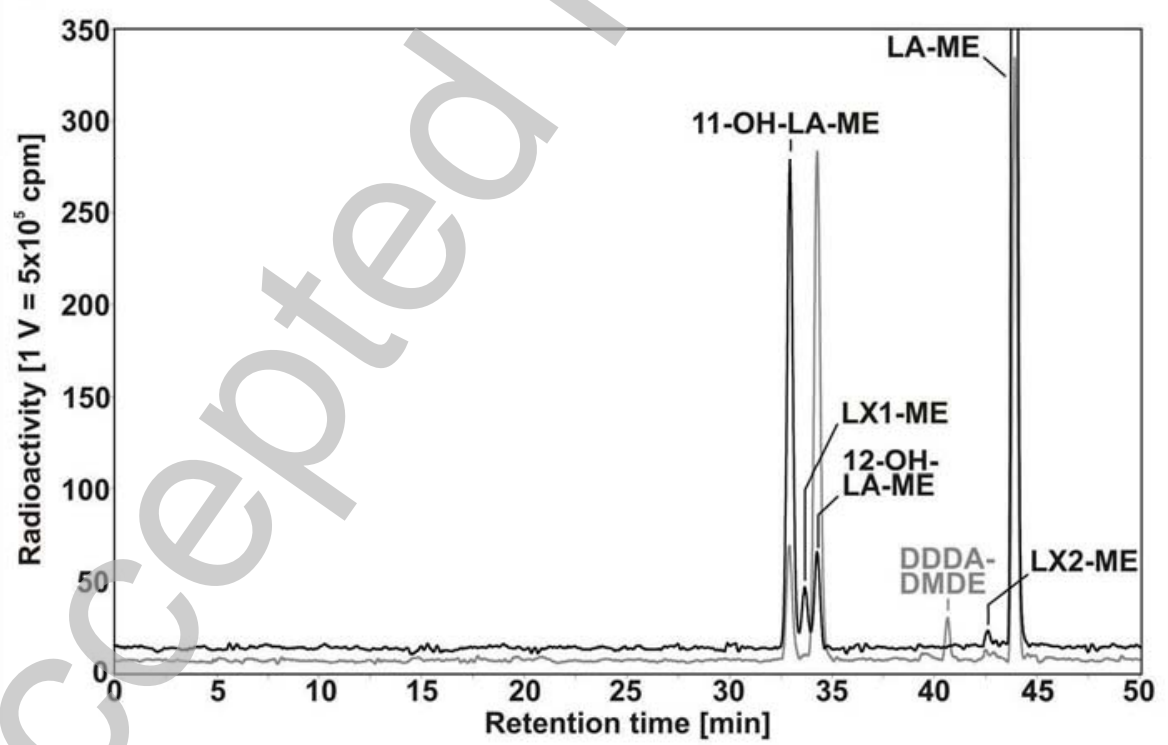


Biochemical Journal Immediate Publication. Published on 11 Feb 2011 as manuscript BJ20101942

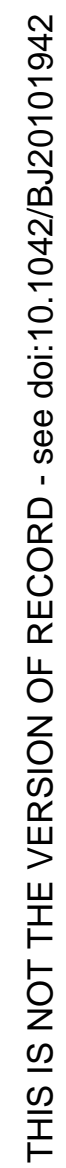

A

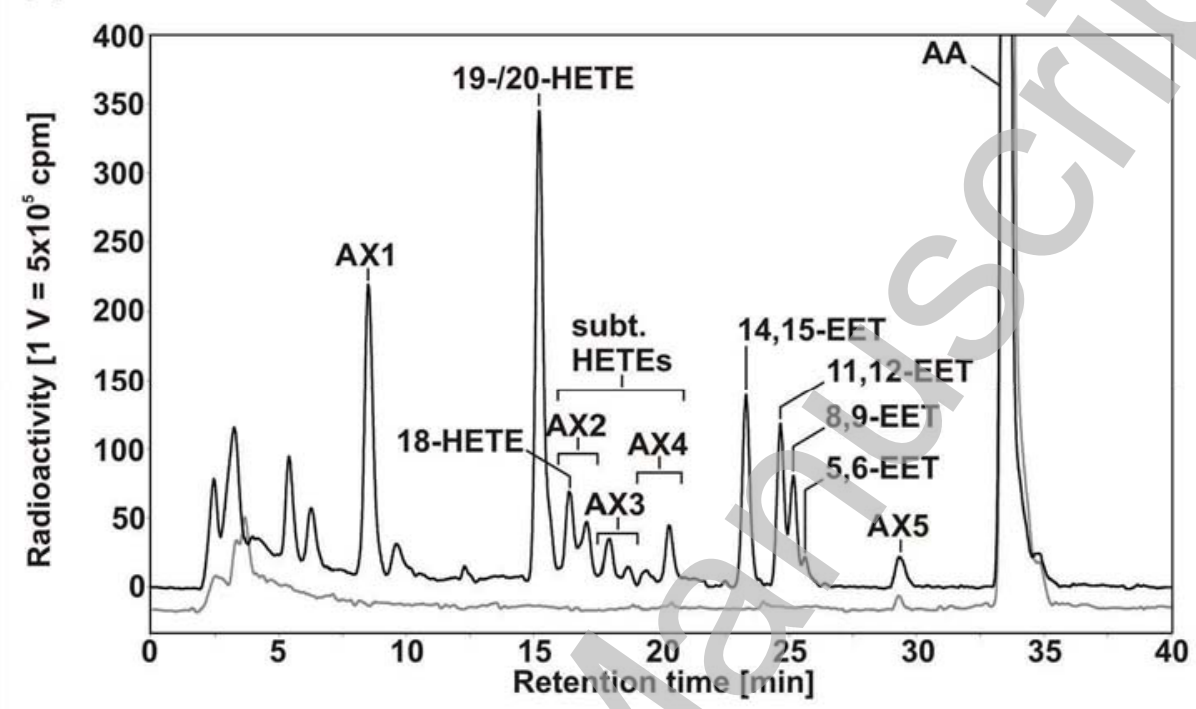

B

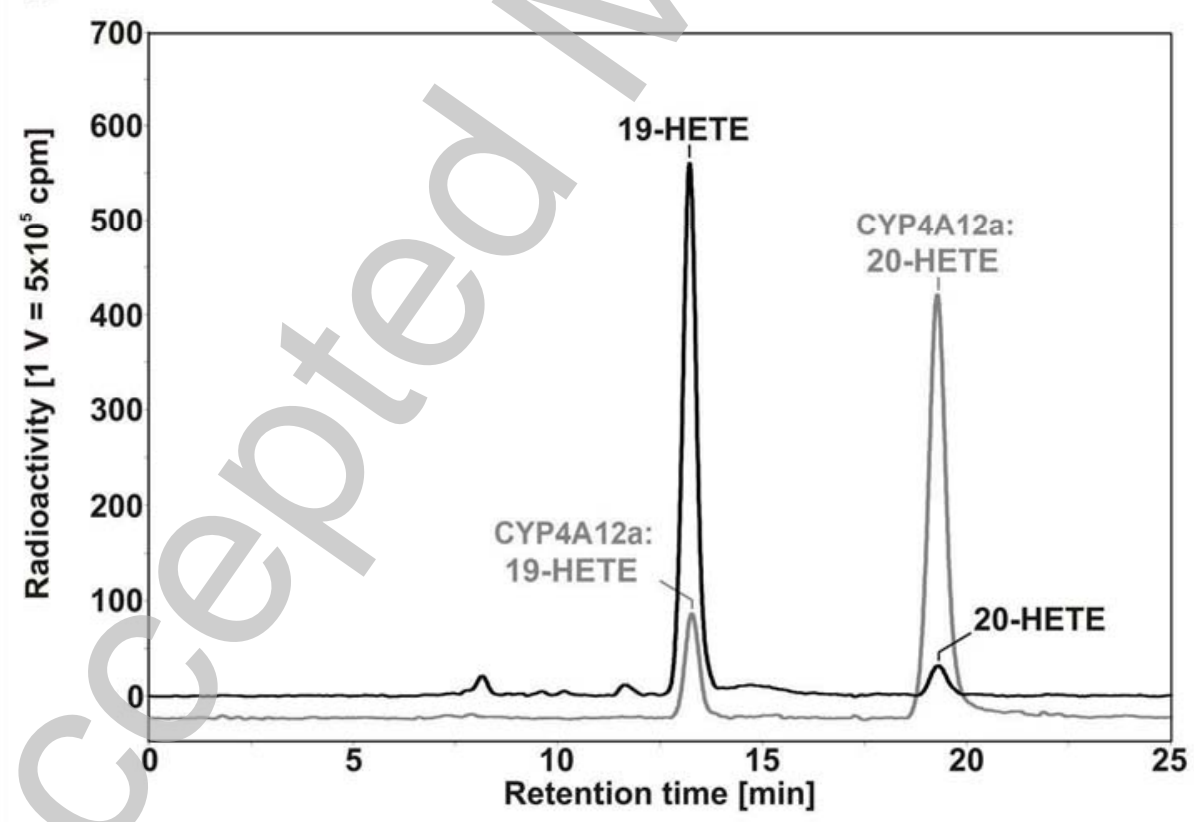

Licenced copy. Copying is not permitted, except with prior permission and as allowed by law. (C) 2011 The Authors Journal compilation (c) 2011 Portland Press Limited 
B Biochemical Journal Immediate Publication. Published on 11 Feb 2011 as manuscript BJ20101942

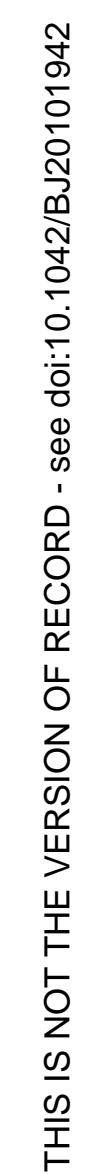

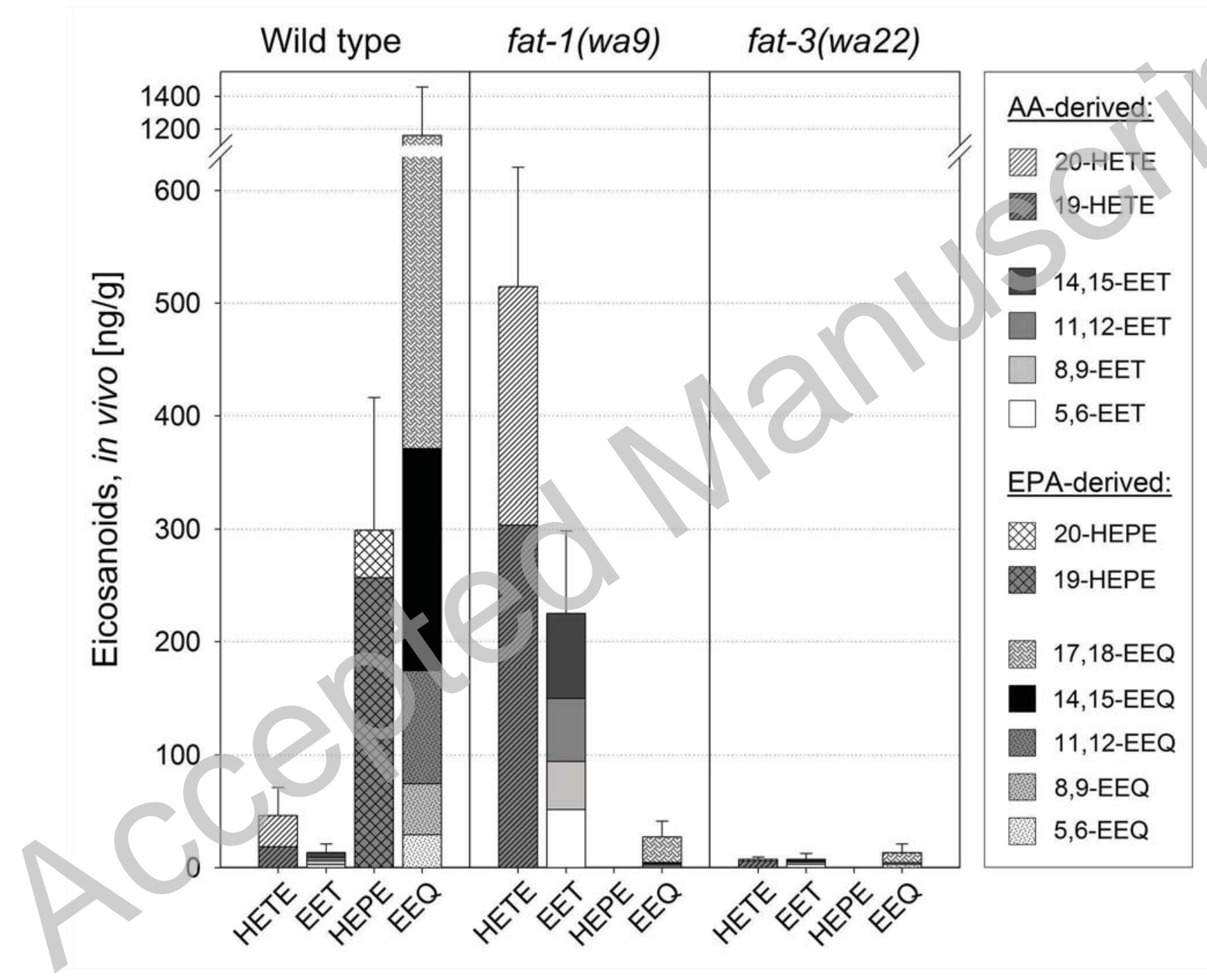


Biochemical Journal Immediate Publication. Published on 11 Feb 2011 as manuscript BJ20101942

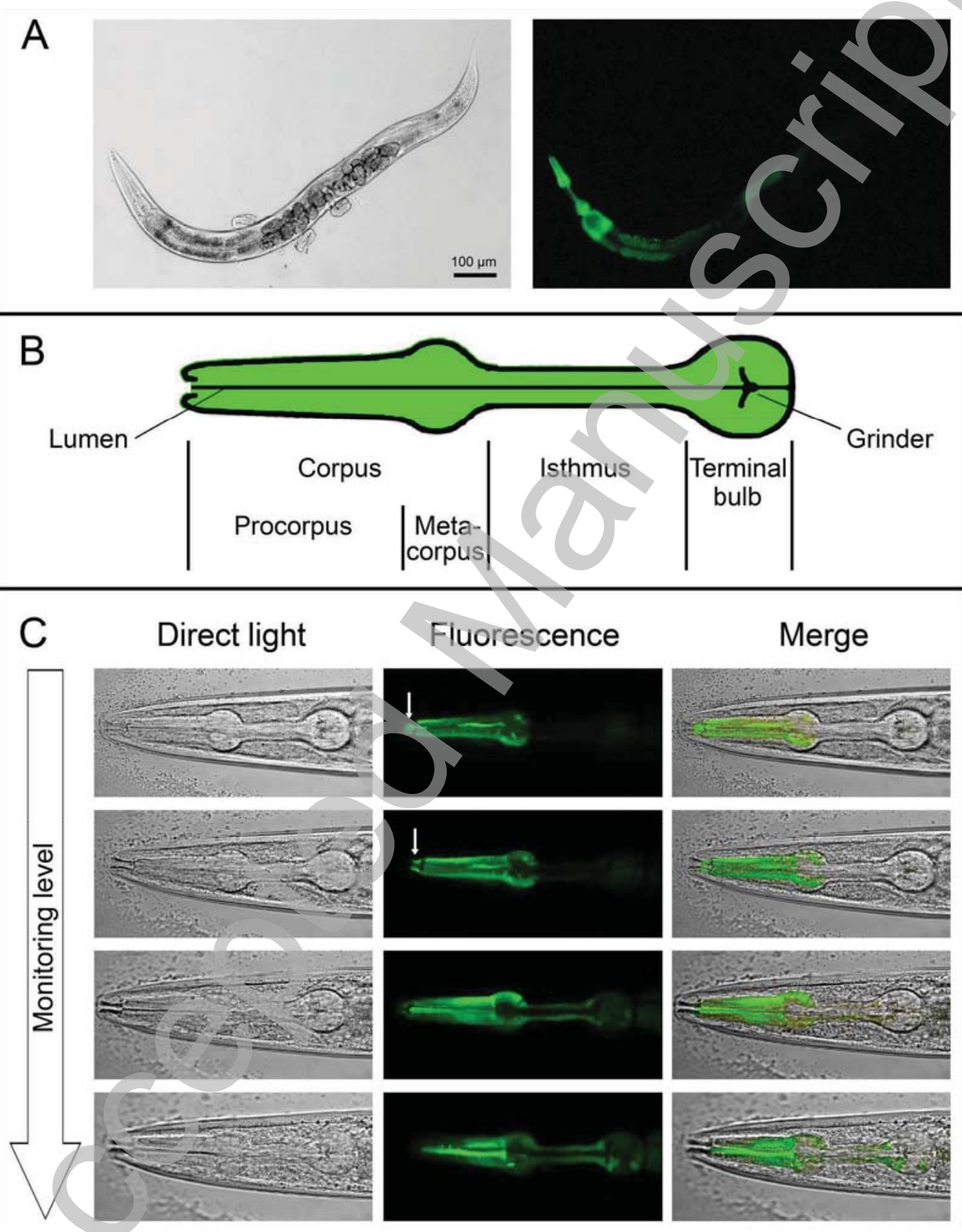


A
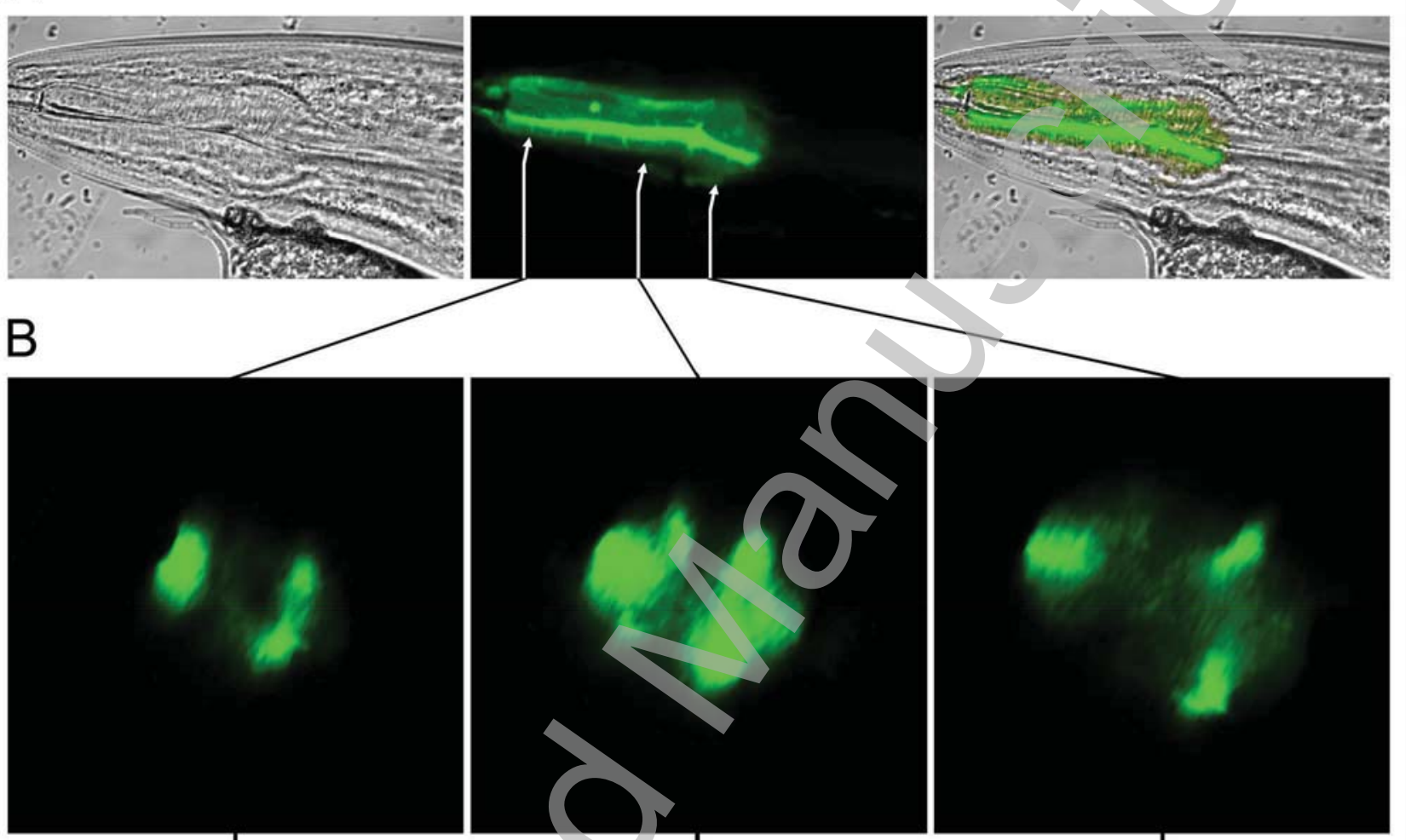

C
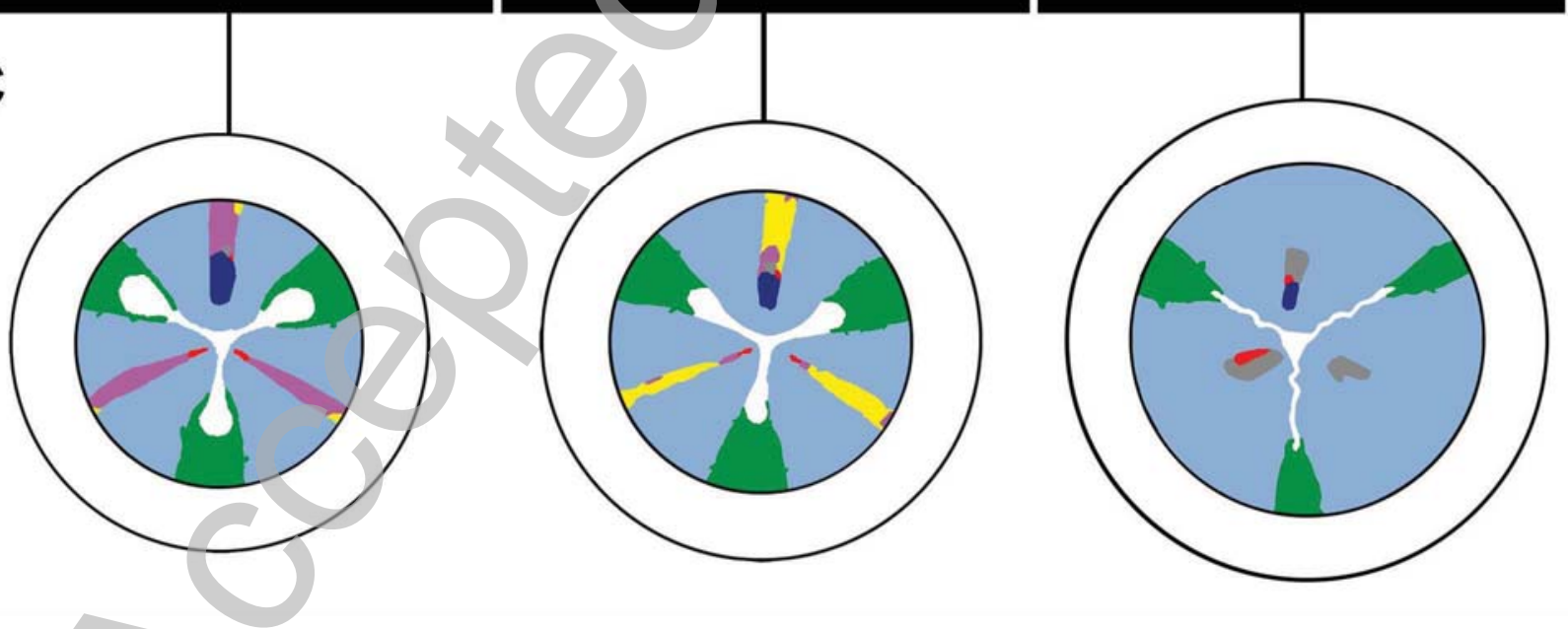

Licenced copy. Copying is not permitted, except with prior permission and as allowed by law. (C) 2011 The Authors Journal compilation (c) 2011 Portland Press Limited 
Biochemical Journal Immediate Publication. Published on 11 Feb 2011 as manuscript BJ20101942

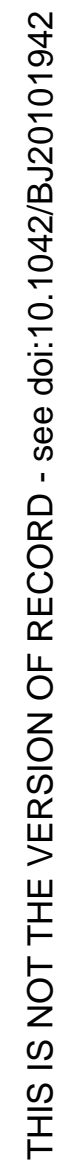
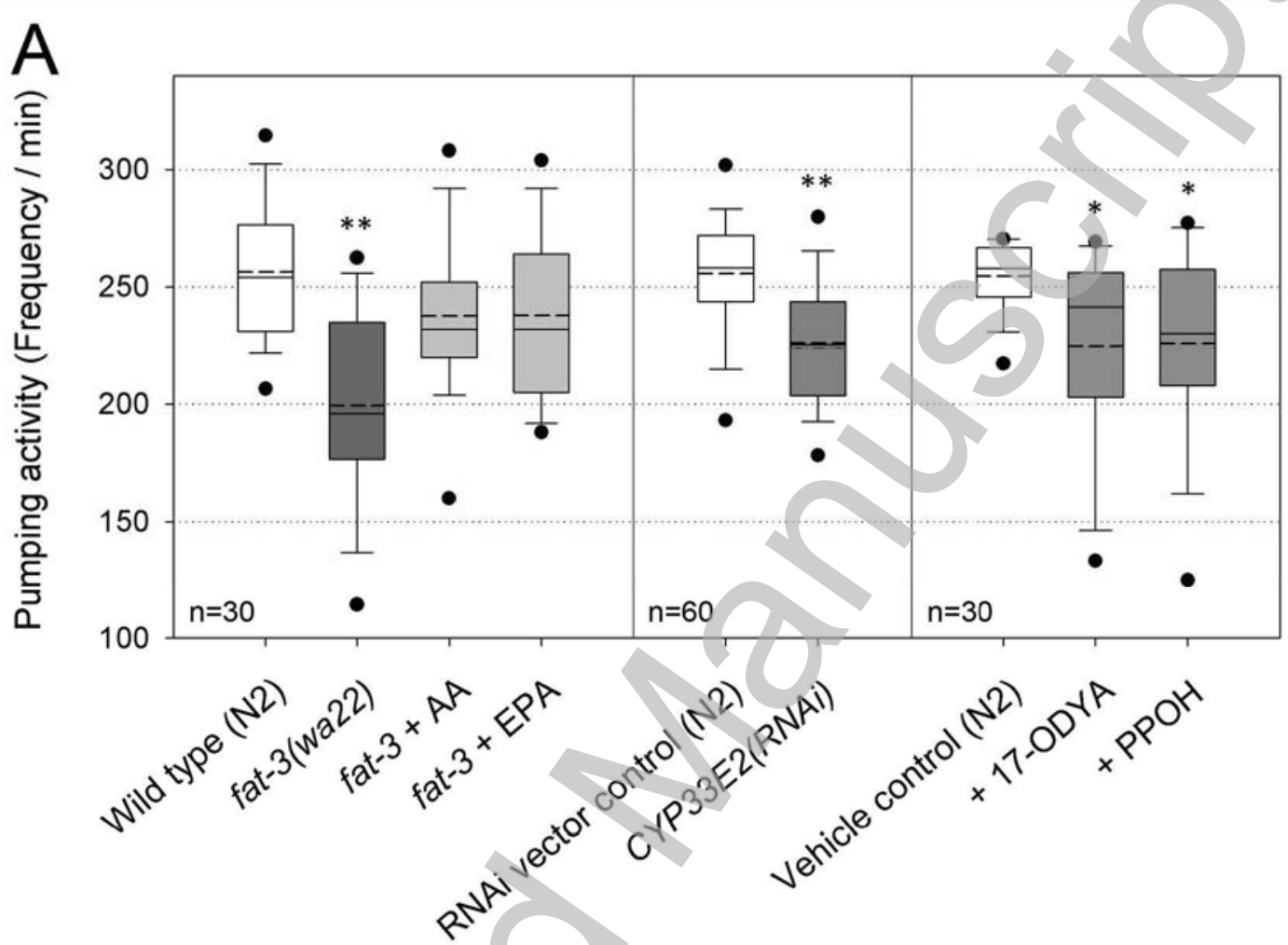

B

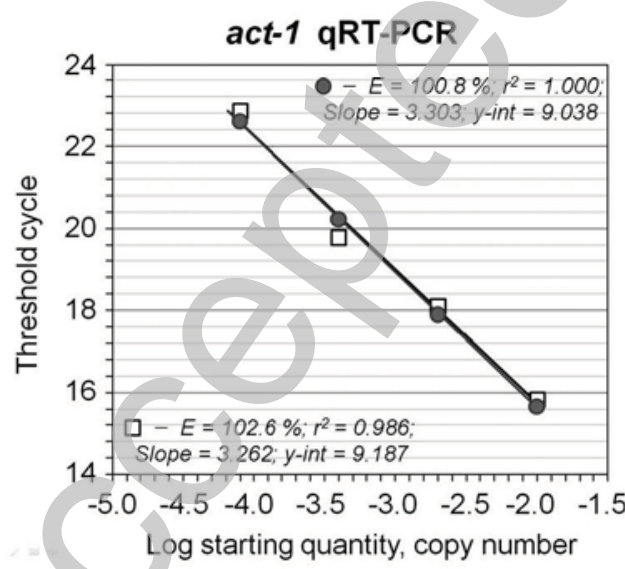

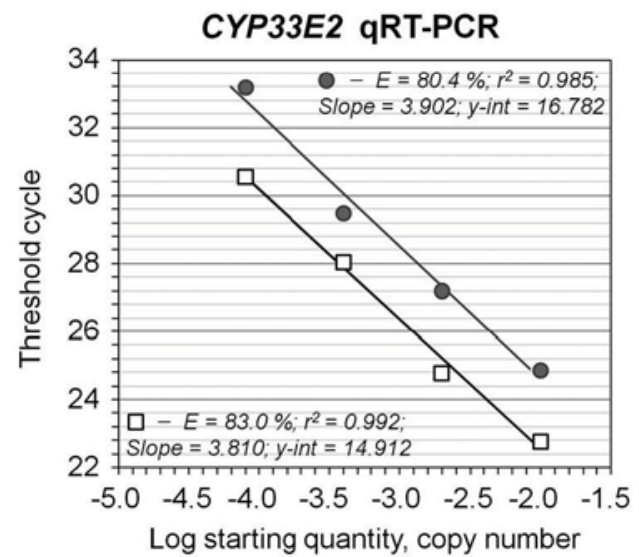

Licenced copy. Copying is not permitted, except with prior permission and as allowed by law. (C) 2011 The Authors Journal compilation (c) 2011 Portland Press Limited 